\title{
Non-Walrasian Labor Markets and Real Business Cycles ${ }^{x}$
}

\author{
Marco Maffezzoli \\ Istituto di Economia Politica \\ Università "L. Bocconi" \\ Via Salasco 3/5 \\ I-20136 Milano \\ Phone: +390258363314 \\ Fax: +390258363309 \\ marco.maffezzoli@uni-bocconi.it
}

This draft: June 13, 2000

The author is heavily indebted to F. Daveri for many fruitful discussions. He owes thanks also to G. Aldashev, T. Boeri, A. Cuñat, C. Häfcke, G. Hansen, M. Marcellino, R. Perotti, and G. Tabellini for useful suggestions. The usual disclaimers apply. 


\title{
Non-Walrasian Labor Markets and Real Business Cycles
}

\begin{abstract}
The standard Real Business Cycle literature mainly focuses on Walrasian models designed to fit the US institutional framework. Differences between the US and Europe, mostly evident in the labor market, suggest that a purely Walrasian model may be inappropriate to study European business cycles. We present a stochastic version of the dynamic general equilibrium model in Daveri and Maffezzoli (2000), where unemployment is generated by monopolistic unions, and calibrate it to reproduce several long-run features of the Italian and US economies. The properties of our model are compared to the corresponding ones of Rogerson and Wright's indivisible labor model. We focus on the standard business cycle statistics, the impulse response functions, and the ability to reproduce the cyclical components of the main macroeconomic variables. We conclude that: (i) the business cycle statistics are observationally equivalent in small samples; (ii) the impulse response functions of the Monopoly Union (MU) model show a higher degree of overall persistence; (iii) the MU model enjoys a statistically significative advantage in reproducing the Italian business cycles, while its alternative seems to better explain the US business cycles.
\end{abstract}

JEL Classification: E32, E24, J23, J51

Keywords: Real Business Cycle, General Equilibrium, Trade Union, Indivisible Labor 


\section{$1 \quad$ Introduction}

The Real Business Cycle (RBC) model, better defined as the Dynamic Stochastic General Equilibrium (DSGE) model, introduced by Kydland and Prescott (1982) and Long and Plosser (1984), for nearly two decades has been considered the profession's workhorse to study business cycles in modern market economies. An impressive research effort has been devoted to solve numerous puzzles left unexplained by the basic model.

The RBC literature traditionally focused on purely competitive models, designed to fit the US institutional framework. However, the institutional differences between the US and Europe, mostly evident in the labor markets, suggest that a purely Walrasian model may be an inappropriate tool to study business cycles in European countries, as advocated in Gali (1996). More generally, Hall (1998) suggests that real frictions are essential to explain employment fluctuations in the modern DSGE framework. ${ }^{1}$

The DSGE methodology has been extended by several authors to incorporate nonWalrasian features. ${ }^{2}$ Our intention is to contribute to this increasing literature by presenting a non-Walrasian DSGE model designed to fit the European, and in particular the Italian, labor market institutions.

Even if the Italian labor market has become more flexible during the 1980s and the 1990s, as described in Bertola and Ichino (1995), it still features a pervading overall rigidity. Its structure is far from the highly competitive one of the US labor market. A striking difference between the two institutional frameworks concerns the role and importance of trade unions.

Table 1 shows that the union density and coverage rates have been consistently higher in Italy than in the US over the last twenty years. The density rate decreased significantly in both countries during the 1980s; however, a considerable drop in the coverage rate followed only in the US. The coverage rate in Italy remained always above $80 \%$, and may have been even higher - almost close to one among the formally employed workers - as suggested in OECD (1997). This empirical evidence strongly suggests that the role of trade

\footnotetext{
1 Gali (1996) develops a dynamic non-Walrasian framework - comprehensive enough to accommodate various labor-market structures - to justify involuntary unemployment in general equilibrium. Hall (1998) surveys the search-theoretic literature and the recent attempts to integrate it into a DSGE framework, discussing the ability of these models to explaining the stochastic properties of US employment.

${ }^{2}$ For a survey on non-Walrasian models, see Danthine and Donaldson (1995). Gomes et al. (1997) and Chari et al. (1998) are some recent contributions.
} 
unions in Italy should be taken into account when the cyclical properties of employment are to be studied.

We take this as a crucial point, and, strictly following Daveri and Maffezzoli (2000), we develop a DSGE model with endogenous growth and equilibrium unemployment, generated respectively by learning-by-doing and monopolistic unions, and calibrate it to reproduce several long-run features of the Italian economy. ${ }^{3}$ Then, we approximate and solve the model using standard numerical methods, and employ the resulting toy economy to answer a specific question, whether the Monopoly Union (MU) model enjoys a comparative advantage over a stochastic version of the Rogerson and Wright (1988) indivisible labor model in explaining the Italian business cycle. ${ }^{4}$

To answer this question, we use three different comparison metrics. First, we compare the models' small sample stochastic properties, focusing on the standard business cycle statistics under the H-P filter. Second, we compare their impulse response functions. Third, we evaluate their relative ability to reproduce the cyclical components of the main Italian macroeconomic time series when fed with the observed shocks to productivity.

As far as the business cycle statistics are concerned, we show that, surprisingly, the two models are almost perfectly observationally equivalent. In other words, both models generate in small samples an extremely similar set of standard business cycle statistics.

Focusing instead on the impulse response functions, we conclude that the simulated series for all main variables tend to be more persistent in the MU model than in the RW. Productivity shocks in the former have a longer-lasting effect than in the latter, since the employment dynamics in the MU model is eventually driven only by the dynamics of the capital (human and physical) stocks. In other words, while both model react similarly to a productivity shock on impact, generating this way comparable business cycle statistics, their adjustment dynamics is significantly different. This difference between adjustment paths depends directly on the labor market structure.

The overall capacity of both models to reproduce the observed Italian quarterly cyclical components is limited. However, the MU model performs consistently better than

\footnotetext{
${ }^{3}$ Gali (1995) builds a DSGE model on similar lines, focusing on the dynamics of unemployment in the US.

4 The basic Rogerson (1988) indivisible labor model was introduced in the RBC literature by Hansen (1985). King and Rebelo (2000) incorporate the more general Rogerson and Wright (1988) setup, that allows for non-separable leisure, in what they propose as the current benchmark RBC model. Our version simply merges the Rogerson-Wright utility function with the production functions, budget constraints, and accumulation equations of the MU model.
} 
its alternative. The correlation coefficients between the observed and simulated series for output and consumption, investment, and employment are respectively 8,4 , and 25 points higher for the MU model. These differences are crucial, since the dimension in which the MU model clearly outperforms the RW, i.e. the dynamics of employment, corresponds to the one that most directly depends on the assumptions characterizing it.

By considering the simulated series as competing forecasts and applying the DieboldMariano testing framework, we can provide a formal argument in favor of the MU model. The prediction mean squared errors generated by the MU model are significantly lower than the corresponding ones generated by its alternative, at least for output, investment, and employment. In other words, the prediction accuracy of the MU model seems significantly higher in a statistical sense.

Our results, then, strongly suggest that the MU model actually enjoys a significant advantage in replicating the Italian business cycles. We conjecture that this advantage comes from a labor-market structure better tailored on the Italian institutional framework. If our conjecture were right, the relative performance of the RW model should improve as the focus moves to a country endowed with a more competitive labor market, as the US.

To test this conjecture, we calibrate our toy models to the US economy, and replicate the previously described set of experiments. Our results suggest that the MU model actually loses any significative comparative advantage, which on the contrary seems inherited by its alternative.

To summarize, both the models are observationally equivalent in small samples, if the focus is on the standard business cycle statistics. By extending the comparison metric, we conclude that the MU model generates more persistence impulse responses, and replicates significantly better the observed Italian business cycles, but not the US ones. The conclusion we may draw is the following: the introduction of non-Walrasian elements in the DSGE framework may help to improve its explanatory power, if the empirical focus is on economies characterized by pervading real rigidities as, for instance, the European ones. Our evidence suggests that these gains may be substantial.

The structure of the paper is as follows: Section 2 presents the set-up of the model, Section 3 the calibration procedure, and Section 4 our results. Concluding remarks are in Section 5 . 


\section{The model}

We present a simplified stochastic version of the model in Daveri and Maffezzoli (2000), which extends the well-known monopoly union model into a full-fledged DSGE framework.

The economy is populated by many identical, infinitely living firms and households.

Firms produce a homogeneous consumption good, combining capital services and labor through a constant-returns-to-scale CES technology subject to persistent but stationary productivity shocks. They behave as price-takers on both the markets for labor and physical capital services. Under these assumptions, firms can be aggregated into a single representative firm.

Each firm is endowed with a pool of households from which it can hire. Each pool contains infinitely many households, so that the individual household member is of measure zero. ${ }^{5}$ Households own both factors of production, physical capital and labor, and each period sell their services to the firms. When supplying these factor services, households face an asymmetry.

The individual supply of capital services is perfectly divisible, since the latter can be sold at the given rental rate in arbitrarily small lots to a large number of firms through a competitive financial market, which effectively acts as a "veil" between households and firms.

The individual labor supply, instead, is indivisible. If employed, each household member works only a fixed number of hours, selling her unit labor endowment to only one firm at a time. Given this asymmetry, all household members in a particular pool, while remaining price-takers in the capital market, perceive the scope for extracting some producer surplus by organizing themselves into a firm-specific trade union. ${ }^{6}$

The unions negotiate the wage on behalf of their members. Note that, though "large" at the firm or sector level, the unions are "small" at the economy-wide level, and thus take the rental price of physical capital and the policy variables as given, as the household members do. The unions act as monopolists on the labor market, and maximize the average labor

\footnotetext{
5 Given constant returns to scale, firms and household pools may be better interpreted as industries or sectors.

6 We do not model explicitly the process of union formation. Horn and Wolinsky (1988) is a classical reference. Westermarck (1999) extends the Horn-Wolinsky results to a general setting, showing that highly substitutable workers have an incentive to form a union when contracting over their wage, while complementary workers don't. Our assumption of identical households is equivalent to perfect substitutability.
} 
income of their members taking the conditional labor demand function of the firm as given. Once the wage has been set, the firm is free to choose the employment rate along its labor demand function. In other words, we adapt to our needs the well-known "monopoly union" model, introduced by Dunlop (1944) and Oswald (1982), which is a particular case of the more general "sequential bargaining" framework proposed by Manning (1987).

At the monopoly wage, some members of the union may remain unemployed. All members face the same $e x$ ante probability of unemployment. If employed, a household member supplies her unit of labor at the monopoly wage rate; if unemployed, she receives an unemployment subsidy from the government. Although being employed or unemployed is unknown ex ante, the unemployed may feel uneasy ex post and leave the union. To tackle this critical issue, the union also pursues a redistributive goal. To preserve its existence, the union redistributes the wage bill among all union members. This extreme form of redistribution guarantees the same ex post labor income to all, independently of labor market outcomes. The union acts as a substitute for complete insurance markets, preserving the agents' homogeneity over time.

Note that, being price-takers on the capital markets, the household members do not realize that the union's behavior simply increases the labor share in income at the expense of the capital one, introducing a deadweight loss that decreases the overall income level. In our set-up, then, the labor share is higher and the income level, together with the employment rate, lower than in a Pareto-efficient allocation.

In the following Section, we analyze in detail the optimization problems of both the firm and the union, describing how the wage equation emerges.

\subsection{The wage equation}

The representative firm produces a homogeneous consumption good using a constant-returns-to-scale technology summarized by the following CES production function:

$$
Y_{t}=a_{t}\left[\alpha K_{t}^{\eta}+\left(n_{t} E_{t}\right)^{\eta}\right]^{\frac{1}{\eta}}
$$

where $\eta<1$ and $\alpha>0$. In our notation, $Y_{t}$ represents the aggregate per-capita output level, $K_{t}$ the aggregate per-capita level of physical capital services, $n_{t}$ the employment rate, $E_{t}$ the aggregate per-capita human capital stock, interpreted as an economy-wide externality, and $a_{t}$ the aggregate Total Factor Productivity (TFP). The factor $n_{t} E_{t}$ corre- 
sponds to labor in efficiency units. The elasticity of substitution between physical capital and labor is equal to $\xi \equiv 1 /(1-\eta)$.

We assume that the TFP follows an exogenous stochastic Markov process, approximated by the following stationary autoregressive process:

$\ln \left(a_{t+1}\right)=\rho \ln \left(a_{t}\right)+\epsilon_{t}$

where $0<\rho<1$ is the persistence parameter and $\epsilon_{t} \sim N\left(0, \sigma^{2}\right)$ the iid innovation.

We extend one of the equilibrium concepts discussed in Anderson and Devereux (1988), and assume that employment rates, wages, and demands for physical capital services are determined in a noncooperative dynamic game between unions and firms. The strategic variables are respectively the contingent wage rates for the unions and the contingent demands for capital services for the firms. The scope for pre-commitment is barred on both sides. In other words, neither unions nor firms can credibly commit, respectively, to a sequence of future wage rates and demands for capital services.

The unions maximize the expected discounted flow of future average labor incomes:

$\max _{\left\{W_{j} \mid a_{j}\right\}_{j=t}^{\infty}} E_{t}\left\{\sum_{j=t}^{\infty} R_{t}^{j}\left[n_{j} W_{j}+\left(1-n_{j}\right) S_{j}\right]\right\}$

where $R_{t}^{j}$ is a time-varying market discount factor and $S_{t}$ the per-capita unemployment subsidy, subject to the conditional demand for labor:

$W_{t}=a_{t}\left[\alpha K_{t}^{\eta}+\left(n_{t} E_{t}\right)^{\eta}\right] \frac{1-\eta}{\eta} n_{t}^{\eta-1} E_{t}^{\eta}$

given the sequences $\left\{K_{j} \mid a_{j}\right\}_{j=t}^{\infty},\left\{E_{j} \mid a_{j}\right\}_{j=t}^{\infty}$, and $\left\{S_{j} \mid a_{j}\right\}_{j=t}^{\infty}$.

The firms, instead, maximize the expected discounted flow of future profits:

$\max _{\left\{n_{j}, K_{j} \mid a_{j}\right\}_{j=t}^{\infty}} E_{t}\left[\sum_{j=t}^{\infty} R_{t}^{j}\left(Y_{j}-W_{j} n_{j}-r_{j} K_{j}\right)\right]$

subject to (1), given the sequences $\left\{W_{j} \mid a_{j}\right\}_{j=t}^{\infty},\left\{r_{j} \mid a_{j}\right\}_{j=t}^{\infty}$, and $\left\{E_{j} \mid a_{j}\right\}_{j=t}^{\infty}$. 
The sequences of employment rates, wage rates, and demands for capital services $\left\{n_{j} \mid a_{j}\right\}_{j=t}^{\infty},\left\{W_{j} \mid a_{j}\right\}_{j=t}^{\infty}$, and $\left\{K_{j} \mid a_{j}\right\}_{j=t}^{\infty}$ - that jointly solve problems (4) and (5) for the given sequences of contingent rental rates, human capital stocks, and unemployment subsidies $\left\{r_{j} \mid a_{j}\right\}_{j=t}^{\infty},\left\{E_{j} \mid a_{j}\right\}_{j=t}^{\infty}$, and $\left\{S_{j} \mid a_{j}\right\}_{j=t}^{\infty}$ - form a Nash equilibrium for the previously described noncooperative game.

Unions and firms effectively solve a sequence of independent games. This is because, (i) the services of physical capital and labor are to be purchased in each period; (ii) precommitment is ruled out; (iii) unions take as given the rental price of capital, as well as the set of policy variables. Hence, unions fail to internalize the dynamic consequences of today's wage setting on capital accumulation. We restrict then our attention to Markov strategies depending only on the current rental rate, the TFP level, the human capital stock, and the unemployment subsidy.

Given our assumptions, the employment rate, the wage rate, and the demand for physical capital services are jointly determined in each period by the following three equations:

$$
\begin{aligned}
& W_{t}=a_{t}\left[\alpha K_{t}^{\eta}+\left(n_{t} E_{t}\right)^{\eta}\right]^{1-\eta} n_{t}^{\eta-1} E_{t}^{\eta} \\
& r_{t}=a_{t}\left[\alpha K_{t}^{\eta}+\left(n_{t} E_{t}\right)^{\eta}\right]^{1-\eta} \alpha K_{t}^{\eta-1}
\end{aligned}
$$

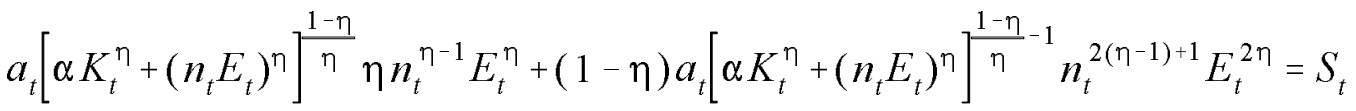

Equations (6) and (7) are the standard conditions equalizing rental rates and marginal productivities. Condition (8) obtains from rewriting the unions's felicity function as:

$$
a_{t}\left[\alpha K_{t}^{\eta}+\left(n_{t} E_{t}\right)^{\eta}\right)^{\frac{1-\eta}{\eta}} n_{t}^{\eta} E_{t}^{\eta}+\left(1-n_{t}\right) S_{t}
$$


and deriving it partially with respect to $n_{t}{ }^{7}$ In turn, we may rewrite the corresponding first order condition as:

$$
\left(\frac{a_{t} n_{t} E_{t}}{Y_{t}}\right)^{\eta}\left[\eta+(1-\eta)\left(\frac{a_{t} n_{t} E_{t}}{Y_{t}}\right)^{\eta}\right]=S_{t} \frac{n_{t}}{Y_{t}}
$$

Equation (10), being highly non-linear, has no close form solution, but defines implicitly the monopoly employment rate and, together with the firm's conditional labor demand function, the corresponding wage. In equilibrium, the employment rate is smaller than one, so that equilibrium unemployment arises; its value depends on the capital stocks, the TFP level, the unemployment subsidy, and the elasticity of substitution between physical capital and effective labor. ${ }^{8}$

The union's problem is graphically described in Figure 1, for given capital stocks and TFP level. The monopoly employment rate is determined at the intersection between the horizontal line corresponding to current unemployment subsidy, that can be interpreted as a fixed "marginal cost", and the downward-sloping curve denoted $m r$, representing the "marginal revenue" of an additional unit of labor. The wage rate is then determined according to the conditional labor demand curve.

\subsection{Intertemporal choice}

Under our assumptions, all household members are and remain effectively identical at any moment in time. Thus, we are allowed to aggregate them into a representative household, whose preferences over consumption streams are summarized by an intertemporal utility function of the form:

$$
U_{t}=E_{t}\left(\sum_{j=t}^{\infty} \beta^{j^{-t}} \frac{\tilde{C}_{j}^{1-\mu}}{1-\mu}\right)
$$

\footnotetext{
${ }^{7}$ Once the labor demand function has been taken into account, the choice of the control variable is irrelevant.

${ }^{8}$ Note that, if $\eta=1$ the production function becomes a "Cobb-Douglas", and the first order condition (4) collapses to $n_{t}=s_{N}^{2}\left(y_{t} / s_{t}\right)$. In this particular case, the employment rate is simply proportional to the current output level.
} 
with $\mu<1$ and $0<\beta<1$. The parameter $\mu$ corresponds to the reciprocal of the intertemporal elasticity of substitution, while $\beta$ represents the intertemporal discount factor. Note that a tilde identifies individual-level variables.

The representative household is subject to the following intratemporal budget constraint:

$\tilde{C}_{t}+\tilde{I}_{t}=r_{t} \tilde{K}_{t}+n_{t} W_{t}+\left(1-n_{t}\right) S_{t}-Q_{t}$

where $I_{t}$ represents investment and $Q_{t}$ a per-capita lump-sum tax, and the following accumulation equation for physical capital:

$\tilde{K}_{t+1}=(1-\delta) \tilde{K}_{t}+\psi\left(\tilde{I}_{t} / \tilde{K}_{t}\right) \tilde{K}_{t}$

where $\delta$ is the depreciation rate. Both constraints must hold each period with probability one.

The function $\psi(\cdot)$ summarizes the adjustment costs related to investment in physical capital ${ }^{9}$. We assume that $\psi>0, \psi^{\prime}>0$, and $\psi^{\prime \prime}<0$; furthermore, in steady-state $\psi=I / K$ and $\psi^{\prime}=1$. The elasticity of the investment-capital ratio with respect to Tobin's $q$ is defined as $1 / \xi_{\psi}$, where $\xi_{\psi} \equiv-\psi^{\prime \prime} \cdot(I / K)$.

The sequences of contingent prices $\left\{r_{t}, W_{t} \mid a_{t}\right\}_{0}^{\infty}$ and aggregate variables $\left\{n_{t}, S_{t}, Q_{t} \mid a_{t}\right\}_{0}^{\infty}$ are taken as given by the representative household.

Under our assumptions, the first order and transversality conditions are jointly necessary and sufficient to solve the representative household's problem.

\subsection{Aggregate constraints}

The government finances the unemployment subsidy by imposing a lump-sum tax on households. In other words, the following aggregate per-capita budget constraint has to hold each period with probability one:

$Q_{t}=\left(1-n_{t}\right) S_{t}$

9 As proved by Hayashi (1982), the reciprocal of $\psi^{\prime}$ corresponds to Tobin's $q$. 
Finally, we assume that the accumulation of human capital takes place through a simple learning-by-doing process, interpreted as a by-product of employment and summarized by the following accumulation equation:

$$
E_{t+1}=E_{t}+\varphi n_{t} E_{t}
$$

where $\varphi$ represents a scale parameter.

\subsection{Equilibrium}

In equilibrium, individual and aggregate per-capita quantities are equal, since all individuals are identical ex ante, and the union's redistributive role guarantees that they remain so ex post.

A recursive dynamic equilibrium for our economy is then defined as:

i) a sequence of contingent prices, $\left\{r_{t}, W_{t} \mid a_{t}\right\}_{0}^{\infty}$;

ii) a sequence of individual consumption levels and physical capital stocks, $\left\{\tilde{C}_{t}, \tilde{K}_{t} \mid a_{t}\right\}_{0}^{\infty}$;

iii) a sequence of aggregate consumption levels and physical capital stocks, $\left\{C_{t}, K_{t} \mid a_{t}\right\}_{0}^{\infty}$;

iv) a sequence of employment rates, $\left\{n_{t} \mid a_{t}\right\}_{0}^{\infty}$;

v) sequences of human capital stocks $\left\{E_{t} \mid a_{t}\right\}_{0}^{\infty}$, unemployment subsidies, $\left\{S_{t} \mid a_{t}\right\}_{0}^{\infty}$, and lump-sum transfers, $\left\{Q_{t} \mid a_{t}\right\}_{0}^{\infty}$;

such that:

i) the individual quantities $\left\{\tilde{C}_{t}, \tilde{K}_{t} \mid a_{t}\right\}_{0}^{\infty}$ solve the representative household optimization problem for the given sequences $\left\{r_{t}, W_{t}, n_{t}, S_{t}, Q_{t} \mid a_{t}\right\}_{0}^{\infty}$;

ii) the aggregate quantities $\left\{n_{t}, K_{t} \mid a_{t}\right\}_{0}^{\infty}$ solve the representative firm's problem for the given sequences $\left\{r_{t}, W_{t}, E_{t} \mid a_{t}\right\}_{0}^{\infty}$;

iii) the individual and aggregate quantities are consistent, $\tilde{C}_{t}\left|a_{t}=C_{t}\right| a_{t}$ and $\tilde{K}_{t}\left|a_{t}=K_{t}\right| a_{t}$;

iv) the good market clears;

v) the employment levels $\left\{n_{t} \mid a_{t}\right\}_{0}^{\infty}$ solve the unions' optimization problem for the given sequences $\left\{r_{t}, S_{t}, K_{t}, E_{t} \mid a_{t}\right\}_{0}^{\infty}$; 
vi) the government budget constraint and the human capital accumulation equation are satisfied.

Substituting the equilibrium conditions and the government budget constraint into the first order and transversality conditions, we obtain a non-linear system of stochastic difference equations that defines the full set of feasible equilibrium allocations.

Given the linearity in the human capital stock of equation (15), the economy may be characterized by endogenous growth as long as $\varphi n_{t}>0 \forall t$. If this is the case, the previously obtained dynamic system is non-stationary, and we have to normalize it with regard to $E_{t}$. Doing so, we loose a state variable but gain a pseudo-control variable, i.e. the endogenous growth rate, defined as $\gamma_{t} \equiv 1+\varphi n_{t}$.

We assume that the unemployment subsidy grows steadily at the endogenous rate, $i e$. that the normalized subsidy remains constant over time at a given level, $s_{t}=s$. This specification is not the only possible one. In an alternative framework, for instance, the subsidy may equal a constant share of current income. Such a specification implies that changes in total factor productivity do not influence at all the employment rate, since the latter would depend capital accumulation only. In our view, such an outcome would clearly contrast with the available empirical evidence.

\section{Calibration}

Being highly non-linear, the normalized system has no closed form solutions. To study its stochastic properties, we apply the well-known solution procedure developed by King, Plosser, and Rebelo (1988). In other words, we assume certainty equivalence, loglinearize the system around its steady-state, and solve it with the Blanchard and Kahn (1980) algorithm.

In our sub-optimal framework, a dynamic equilibrium does not necessarily exist for all possible parameterizations. The existence of a dynamic equilibrium for the original model under a given parameterization reflects into the existence of a stable saddle-path for the corresponding log-linearized system.

To actually solve the approximated system, then, we need to specify a particular parameterization. It turns out that its dynamics depends only on a subset of the parameters. In particular, it depends on the elasticity of intertemporal substitution, $\mu$, the intertemporal discount factor, $\beta$, the elasticity of substitution between capital and labor, $\xi$, the inverse of 
the investment-capital ratio elasticity, $\xi_{\psi}$, the depreciation rate, $\delta$, the relative weight of capital in the CES production function, $\alpha$, the persistence parameter $\rho$, and the standard deviation of productivity shocks, $\sigma$.

We assume that the first three are respectively equal to $\mu=2, \beta=0.99$, and $\xi=0.70$. The first two figures are standard in the literature. The elasticity of substitution between capital and labor has been taken from Pissarides (1998); we perform an extensive sensitivity analysis on this parameter.

The technological parameter $\alpha$ and the depreciation rate $\delta$ are calibrated to reproduce the observed long-run quarterly investment share, capital-output ratio, and growth factor in Italy. All of them are obtained from the recently revised ISTAT series, ${ }^{10}$ spanning from 1982 to 1998, expressed in constant 1995 prices. Output is approximated by Real GDP, investment by Real Gross Fixed Investment, and capital by the Real Total Net Capital Stock; all variables are normalized with respect to the working age population. The growth factor, the investment share and the capital-output ratio are, respectively, $\gamma=1.0048$, $s_{i}=0.20$, and $k / y=12.73$. The implied values for the calibrated parameters are $\alpha=1.15$ and $\delta=1.05 \%$.

The persistence parameter and the standard deviation of productivity shocks can be estimated by fitting an AR(1) model on an empirical measure of quarterly TFP. To obtain the latter, we start by constructing an approximated quarterly series for the physical capital stock, since only annual observations are available ${ }^{11}$. Then, we estimate the initial level of human capital, $E_{0}$, by running a non-linear regression on:

$\ln \left(Y_{t}\right)=\frac{1}{\eta} \ln \left[\alpha K_{t}^{\eta}+\left(n_{t} E_{0} \prod_{j=0}^{t} \gamma_{j}\right)^{\eta}\right]$

\footnotetext{
${ }^{10}$ The Italian National Accounts series have recently been revised and reorganized according to the SEC95 standard. The revised quarterly series are available from 1982:I to 1999:4. Annual observations for the net capital stock are currently available only from 1982 to 1998.

${ }^{11}$ For each year, given the observed initial physical capital stock and the quarterly figures for gross fixed investment, we numerically solve for the quarterly depreciation rate that generates, through the permanent inventory method, the next-year observed initial capital stock. Then, the yearly series for physical capital, the quarterly series for gross fixed investment, and the previously obtained yearly series for the quarterly depreciation rate jointly imply an approximated series for the quarterly physical capital stock. The implied depreciation rates vary slightly over time, and seem to increases sensibly at the beginning of the 1990s. However, this variability reflects a change in the composition of physical capital more than the effect of variable capital utilization, since the observed time series was constructed assuming asset-specific constant depreciation rates.
} 
where all parameters assume their calibrated values, and $\gamma_{t}=1+\varphi n_{t}{ }^{12}$

We use seasonally adjusted quarterly ISTAT series from 1982:1 to 1998:4, expressed in constant 1995 prices. Output is approximated by Real GDP and employment by the Standard Units of Labor, ${ }^{13}$ again, both series were normalized with respect to the working age population.

The residuals generated by this procedure, plotted in Figure 2, represent the approximated ${ }^{14}$ series for the logarithm of TFP. By fitting an AR(1) model on these residuals, we obtain estimates for the persistence parameter and the standard deviation of productivity shocks ${ }^{15}$. The resulting figures are $\rho=0.87$ and $\sigma=0.0056$.

Given the previous parameterization, the elasticity of the investment-capital ratio is calibrated to reproduce the observed relative volatility of investment - measured as the ratio between the standard deviation of the H-P cyclical component of investment and the H-P cyclical component of output (see Table 2) - and equals $\xi_{\psi}=0.076$. To summarize, we obtain the following benchmark parameterization:

$$
\begin{gathered}
\mu=2, \quad \beta=0.99, \quad \xi=0.70, \quad \alpha=1.15, \quad \delta=1.05 \% \\
\gamma=1.0048, \quad \rho=0.87, \quad \sigma=0.0056, \quad \xi_{\psi}=0.076
\end{gathered}
$$

\footnotetext{
${ }^{12}$ To calibrate the scale parameter $\varphi$, we simply substitute the long-run employment rate - equal to 0.58 and the growth factor in $\varphi=(\gamma-1) / n$; the implied value is $\varphi=0.0082$.

${ }^{13}$ The Standard Unit of Labor series combines raw employment data with national accounting information to obtain the equivalent number of workers effectively employed for a standard unit of time.

${ }^{14}$ The model at hand does not explicitly incorporate variable capacity utilization and labor dynamics along the intensive margin. The residual estimated with our procedure is then only a proxy for an empirically based measure of TFP; this proxy, however, is consistent with our theoretical framework. We may agree with Robert Solow, and consider these residuals as a measure of our ignorance.

${ }^{15}$ There is no evidence against the null hypothesis of these shocks being real innovations. The Jarque-Brera test generates a $p$-value equal to 0.86 , so that the null hypothesis of normality cannot be rejected. Furthermore, the Breusch-Godfrey serial correlation LM test (two lags included) generates a $p$-value equal to 0.41 , so that also the null hypothesis of serial uncorrelation cannot be rejected. Finally, the ADF statistic (again, two lags included) equals -4.25 , while the $1 \%$ critical value is -2.60 ; the null hypothesis of a unit root can be safely rejected. We repeated the procedure for different values of the elasticity of substitution between labor and capital, using the corresponding calibrated values for the other parameters, and obtain similar results.
} 


\section{$4 \quad$ Results}

Table 2 summarizes the standard business cycle statistics for the main Italian macroeconomic variables. The table is based on seasonally adjusted quarterly ISTAT series from 1982:1 to 1998:4, expressed in constant 1995 prices. Output is approximated by GDP, consumption by the households' final consumption expenditure, investment by the gross fixed investment, and employment by the Standard Units of Labor. The average labor productivity is constructed as the ratio between output and employment. All variables were normalized with respect to the working age population (except average productivity and TFP), transformed in logarithms, and H-P filtered.

The statistics presented are the standard deviation, the relative volatility (the ratio between the standard deviation of each variable and the standard deviation of output), the autocorrelation coefficient, the correlation coefficient with output, and the correlation coefficient with average productivity. We note that consumption is relatively more volatile than employment, and that investment is more persistent than both output and consumption. Furthermore, the correlation of employment with output is positive but relatively low, while, as expected, its correlation with the average productivity of labor is strictly negative.

\subsection{Small sample properties}

Table 3 summarizes the small sample properties of the MU model under our benchmark parameterization, and is based on a set of 1000 simulations over a 68 quarters horizon - the sample size of observed data. It describes the empirical distribution of our statistics of interest, reporting their averages and standard deviations over the whole set of simulations. The simulated series were H-P filtered for comparison purposes.

The first point to note is that the average standard deviation of output generated by the MU model is higher than the observed one, 1.14 against 0.91 . The internal propagation mechanism seems able to enhance the effect of productivity shocks, so that the same variability of output can be generated by less volatile technology shocks.

However, the model fails to reproduce the high relative volatility of both consumption and employment. The simulated relative volatilities are equal on average respectively to 0.43 and 0.67 , while the observed ones are 0.94 and 0.86 . Note, furthermore, that the 
model fails to reproduce their rank, since consumption is more volatile in the data, while employment is more volatile in the model. ${ }^{16}$

The simulated autocorrelation coefficients are consistently lower than the observed ones. Note that investment is the more persistent variable in the data, but the less persistent one in the model, while the remaining variables - namely consumption, employment, and output - preserve their rank.

All the simulated series are highly procyclical; employment, in particular, is almost perfectly correlated with output. The last result is unsurprising, since the dynamics of employment is driven only by shifts in the conditional labor demand curve which are strictly related to the dynamics of output. The model's behavior sharply contrasts with the observed correlation coefficient of employment with output, equal to only 0.53

Finally, the MU model, at least in its current form, is unable to solve the long-lasting "average productivity" puzzle, since the correlation of employment with the average productivity of labor is significantly positive and equal to 0.98 , while the observed one is significantly negative and equal to -0.36 .

In Table 4 we summarize the results of a sensitivity analysis on the elasticity of substitution between capital and labor, $\xi$. The variation range goes from 0.4 to 1 , the "Cobb-Douglas" case. As we can see, the elasticity of substitution has a strong effect on the model's small sample stochastic properties. In particular, the relative volatility of employment is clearly increasing in $\xi$, going from 0.15 to 1 , since in the "Cobb-Douglas" case the employment rate is directly proportional to the output level. The relative volatility of average productivity is instead decreasing in $\xi$, going from 0.97 to 0 . Note, furthermore, that the correlation of employment with output is less that perfect only for elasticities equal or below 0.6 , while the relative volatility of employment reaches the observed value only for elasticities higher than 0.8 . There is an evident trade-off between relative volatility and correlation with output.

These results tell us that, if the goal is to reproduce the stochastic properties of the H-P filtered Italian quarterly series, the overall performance of the MU model under our benchmark parameterization is still inadequate. However, the described deficiencies are common among the class of one-sector, infinitely-living representative-agent business cycle models, and our model was not specifically designed to overcome them.

\footnotetext{
${ }^{16}$ The reader familiar with the stochastic Brock-Mirman model will not be surprised. A low volatility of consumption is typical in models were the marginal utility of consumption is independent from leisure.
} 


\subsection{Monopoly Union vs. Rogerson-Wright}

We are now interested in evaluating the relative performance of the MU model by comparing it to a standard Walrasian model. We choose a stochastic version of the RW model as our alternative because, as in the MU model, the dynamics of labor takes place along the extensive margin only.

The RW setup is extensively described in King and Rebelo (2000, pp. 46-49). Each household member has to choose between working a fixed number of hours (normalized to one) and not working at all. The choice set is not convex, but may be convexified by introducing employment lotteries. By entering a lottery, a household member can choose to work a fraction $n$ of his days and to remain unemployed the other $1-n$ days.

Under perfect risk-sharing, i.e. assuming complete asset markets, it can be shown that the stand-in representative agent maximizes an intertemporal utility function of the form:

$$
U_{t}=E_{t}\left[\sum_{j=t}^{\infty} \beta^{j-t} \frac{\tilde{C}_{j}^{1-\mu} v\left(1-\tilde{n}_{j}\right)^{1-\mu}}{1-\mu}\right]
$$

where:

$v\left(1-\tilde{n}_{t}\right) \equiv\left[\tilde{n}_{t} v_{1}^{\frac{1-\mu}{\mu}}+\left(1-\tilde{n}_{t}\right) v_{2}^{\frac{1-\mu}{\mu}}\right]^{\frac{\mu}{1-\mu}}$

while $v_{1}$ is the utility of working the fixed shift, and $v_{2}$ the utility of being unemployed.

To obtain the first-order conditions, we form a Lagrangian by combining (18) with equations (6), (7), (12), and (13), and derive it with respect to $\tilde{C}_{t}, \tilde{n}_{t}$, and $\tilde{K}_{t+1}$. The firstorder and transversality conditions are then normalized and combined with the aggregate constraints (14)-(15) and the equilibrium conditions to obtain a system of stochastic difference equations describing the feasible equilibrium allocations. Finally, the system is solved with the usual King-Plosser-Rebelo procedure, and simulated using the previously described benchmark parameterization. 
The RW model has two important features. First, even if household members have an extremely low elasticity of labor supply, ${ }^{17}$ the stand-in representative individual has an infinite $\lambda$-constant elasticity of labor supply, ${ }^{18}$ i.e. the elasticity of her labor supply is infinite for any given shadow value of the installed physical capital. Second, the positive unemployment rate arising in equilibrium is optimal, since individuals freely choose to bear some uncertainty by entering the employment lottery.

Note that the MU model is endowed with the same two features. First, the aggregate wage-setting function can be positively sloped even if the elasticity of individual labor supply is extremely low. ${ }^{19}$ Second, unemployment is optimal for the household members given their price-taking behavior on the market for capital services, since union membership is completely voluntary.

In some sense, then, the MU and RW models provide solutions to the same problems by using two completely different setups. The MU model assumes non-competitive labor markets and does not rely on complete asset markets, while the RW model assumes the existence of both employment lotteries and complete asset markets.

\subsubsection{Small sample properties}

The small sample properties of both models, and in particular the standard business cycle statistics under the H-P filter, are compared in Table 5. The immediate, striking conclusion is that they are almost perfectly observationally equivalent. ${ }^{20}$

To obtain an economic intuition of the mechanisms at work, recall Figure 1. In the MU model, a positive productivity shock shifts both the conditional labor demand curve and the "marginal revenue" ( $m r$ ) curve to the right. The shift in the $m r$ curve, however, is less than proportional. If so, both the wage and employment rates increase.

In the RW model, the positive productivity shock still shifts the conditional demand curve to the right. For a given value of the Lagrange multiplier, the labor supply curve is

\footnotetext{
17 An extensive empirical literature supports this view; a classical, but still valuable, reference is Pencavel (1986).

18 The $\lambda$-constant elasticity corresponds to the elasticity of the Frisch labor supply schedule.

19 Both the household production framework developed by Benhabib et al. (1991) and the search-theoretic framework discussed in Hall (1998) feature the same property. Note that our approach is compatible with a search-theoretic model of the labor market, and may actually be profitably integrated in it.

${ }^{20}$ The RW model implies a slightly higher relative volatility of consumption and a slightly lower volatility of investment. This is because in that model utility is indivisible between leisure and consumption.
} 
perfectly elastic, i.e. a straight line crossing the vertical axis at the equilibrium wage rate. In such a partial equilibrium setting, the shift in the demand curve translates into a more pronounced increase in employment, since the wage rate remains constant (see King and Rebelo, 2000, pp. 48-49). In general equilibrium, however, the labor supply curve shifts upwards, driven by the reaction of current Lagrange multiplier - the shadow price of installed physical capital - to the productivity shock.

In both models, then, a positive shock to productivity is followed by an increase in the wage and employment rates, even if the mechanisms at work are completely different. Nothing guarantees a priori that the magnitude of these changes will be the same across models, ceteris paribus.

Our results suggest that, under the benchmark parameterization, they are, on average, extremely similar, since all the statistics regarding employment are almost identical across models. If the reaction of employment on impact is similar, also the reaction of output, consumption, and investment will be so, and the observational equivalence follows.

To conclude, this numerical exercise shows that a non-Walrasian stochastic general equilibrium model like the MU may be observationally equivalent to a fully Walrasian model like the RW, if the focus is limited to the standard business cycle statistics, which are clearly not discriminating enough. To further evaluate the models' relative performance, we need to extend our comparison metric.

\subsubsection{Impulse response functions}

In Figures 3 to 6 we plot the impulse responses - expressed in percentage deviations from the steady-state - to a $1 \%$ positive productivity shock for the normalized output, consumption, and investment levels, the employment rate, the average labor productivity, the rental and wage rates, and the normalized physical capital stock, respectively for the MU and RW model.

By comparing Figures 3 and $\mathbf{4}$, we note that, on impact, the employment rate rises similarly in both models. Its deviation is however more persistent in the MU model, while the deviation of the average labor productivity is more persistent in the RW. A direct consequence is that the MU model shows a higher persistence in output, consumption, and investment. Furthermore, while in the RW model the deviation of employment turns negative at some point and then converges to the steady-state from below, - as common in models where employment enters the utility function - it converges monotonically from above in the MU model. 
Comparing, instead, Figures 5 and $\mathbf{6}$, we note that the dynamics of the both the wage and rental rates is sensibly different. On impact, the wage rate increases by the same amount in both models; ${ }^{21}$ then, it converges monotonically to the steady-state in the $\mathrm{MU}$ model, but turns negative at some point and converges to the steady-state from below in the RW model. The rental rate, instead, converges quickly in the MU model, while remaining persistently high in the RW model. Finally, we note that the dynamics of physical capital is more pronounced and persistent in the MU model; after 68 quarters, the physical capital stock is still more than 0.40 points higher in the MU model, while only 0.15 points higher in the RW model.

To conclude, the simulated series for output, consumption, investment, employment, wage rate, and physical capital generated by the MU model tend to be more persistent than the corresponding series generated by the RW model. Thanks to the particular internal propagation mechanism, productivity shocks in the MU model have a longer-lasting effect on almost all aggregate variables.

As stressed by Hall (1998), persistence is a critical property of the data that the standard neoclassical model is unable to reproduce. In the RW model, the persistence in all impulse responses depends directly on the persistence of the exogenous driving process. In the MU model, instead, there is an endogenous mechanism that independently introduces persistence in employment, and consequently in the other main variables.

The economics behind this numerical result is straightforward. In the MU model, employment is jointly driven by the dynamics of TFP and both capital stocks. While the TFP is mainly responsible for its reaction on impact, the human and physical capital stocks become quickly the main driving forces, as the TFP converges back to its steady-state level. The deviation of employment, then, persists as long as the deviation of both capital stocks does. On the other hand, a persistent variation in employment has a direct and persistent effect on output, consumption, and, of course, investment. The dynamics of employment and physical capital, in a sense, reinforce each other.

\subsubsection{Observed vs. simulated time series}

Both models can easily be fed with the innovations to the observed TFP series plotted in Figure 2. We compare the observed and the so obtained simulated normalized time series for output, consumption, investment, and employment, expressed as percentage

\footnotetext{
${ }^{21}$ The economic intuition provided in the previous Section seems to be confirmed: the reaction on impact of both the employment and the wage rates is extremely similar across models.
} 
deviations from their mean. ${ }^{22}$ These transformed series can be considered as cyclical components isolated by extracting a linear trend from the logarithms of the original ones. Figure 7 provides a visual comparison, while Table 6 summarizes the correlation coefficients between the observed series and various lags and leads of the corresponding simulated ones.

A quick visual inspection suggests that the overall capacity of both models to reproduce the observed series, and in particular the series for consumption and employment, is limited. Only the dynamics of the output level is reproduced sufficiently well, though this is unsurprising if we recall how the innovations to TFP are computed.

This first impression is confirmed by Table 6. The contemporaneous correlation coefficients between the observed and simulated series are positive, but significantly lower than one. The MU model consistently outperforms the RW, since the simulated series generated by the former are all more correlated with the observed ones than the series generated by the latter. In particular, the differences in favor of the former amount respectively to 8,4 , and 25 points for output and consumption, investment, and employment.

These differences can hardly be dismissed as irrelevant. The dimension along which the MU model enjoys the most evident comparative advantage, i.e. the employment rate dynamics, is also the dimension that directly depends on the labor market structure. The latter is also the main characteristic that distinguishes the two models. In other words, the MU model outperforms the RW model exactly in the dimension that mostly depends on the set of assumptions that characterize it, and which are more consistent with the actual institutional framework in Italy.

In the previous Section, we noted that the reaction of employment on impact is similar across models; as a consequence, the reaction of output, consumption, and investment will be similar too, and the observational equivalence regarding the standard business cycle statistics follows. We noted furthermore that the MU model is characterized by a higher persistence along the subsequent transition paths.

22 We normalize the observed series with respect to a proxy for the human capital stock, defined as $E_{t}=E_{0} \prod_{j=0}^{t} \gamma_{j}$, and transform them into logarithms. Under our assumptions, the resulting series should be stationary. Then, we subtract form each series the corresponding mean. The results may be interpreted as approximated percentage deviations from the steady-state. More precisely, since the previously calculated averages may actually not coincide with the steady-state values, they should be considered as the cyclical components obtained by fitting a (constant) linear trend on the normalized series in logarithms. If the growth rate were constant, this procedure would extract a linear trend from the logarithm of the original series too. Being the simulated series already normalized and expressed as percentage deviations from the steady-state, we simply subtract from each one the corresponding mean to obtain comparable cyclical components. Note that the cyclical components are isolated by extracting the same - up to a constant - linear trend from each variable. By applying the H-P filter to both the observed and simulated series, instead, series-specific trends would be extracted. This may spuriously increase homogeneity across models. 
These properties should reflect into the autocorrelation functions of the simulated series. In Figure 8, we plot the autocorrelations at different lags for the simulated employment rates. As expected, the MU model generates a more persistent series, even if the difference is not dramatic. Furthermore, the differences between the MU and RW autocorrelations increase with the lag, reaching a maximum after five quarters. Again, this confirms that the reaction on impact is similar, while the higher persistence during the transition dynamics affects the stochastic properties only in the medium-run.

\subsubsection{Simulated series as competing forecasts}

By considering the simulated cyclical components as competing forecasts we can provide a formal argument in favor of the MU model by applying the testing framework developed in Diebold and Mariano (1995) and extended in Harvey et al. (1997).

First, we regress the observed series over each simulated series in turn, i.e. we estimate the equation $x_{t}=b \tilde{x}_{i t}+\epsilon_{t}$, where $x_{t}$ is a generic observed series, $\tilde{x}_{i t}$ the corresponding simulated one, and $i$ an index identifying the competing models. Results are reported in the first part of Table 7.

Note that coefficient in the employment equation is significant at the $1 \%$ level for the MU model, but not even at the $5 \%$ for the RW. Furthermore, the $R^{2}$ statistic is uniformly higher for the series generated by the MU model. In particular, while a $21 \%$ of the variance of the observed employment rate can by explained by the MU model, only a tiny $4 \%$ can be explained by its alternative.

Second, we repeatedly estimate the previous equations by recursive least squares. At each step, the last estimate of the parameter vector is used to predict the next value of the dependent variable. The one-step ahead forecast errors resulting from these predictions, suitably scaled, are plotted in Figure 9.

We use these forecast errors to test wether the Prediction Mean Squared Errors (PMSEs) are equal or not, and compute the Modified Diebold-Mariano (MDM) statistic, ${ }^{23}$ reported in the second part of Table 7 together with the corresponding $p$-value.

These results suggest that the PMSEs generated by the MU model are significantly lower than the corresponding ones generated by its alternative - at least for output, invest-

\footnotetext{
${ }^{23}$ The Diebold and Mariano (1995) test was modified by Harvey et al. (1997) to avoid over-sizing in small samples. The Modified Diebold-Mariano statistic is computed by regressing the difference of the squared forecast errors on a constant. The standard $t$-statistic so obtained is multiplied by $(n-1) / n$ to correct for the sample size and then compared with critical values from a Student's $t$-distribution with $n-1$ degrees of freedom.
} 
ment, and employment. In particular, the null hypothesis of equal PMSEs can be rejected at the $1 \%$ level for both output and employment.

In other words, our results suggest that the overall prediction accuracy of the MU model is significantly higher. Only as far as consumption is concerned, the null hypothesis of equal PMSEs cannot be rejected.

\subsection{A comparison: the United States}

In the previous Sections, we provided evidence suggesting that the MU model outperforms the RW in explaining the observed Italian business cycles. This happens, we conjecture, because the former is characterized by a labor market structure better tailored on the Italian institutional framework. If this is the case, the MU model should, at least, not display any comparative advantage in replicating the US business cycles, under the null hypothesis that the US labor market is indeed a highly competitive one.

To check this possibility, we calibrate the models to reproduce the long-run properties of the US economy. As before, we assume $\mu=2, \beta=0.99$, and $\xi=0.70$. To calibrate the technological parameter $\alpha$ and the depreciation rate $\delta$ we obtain the observed long-run quarterly investment share, capital-output ratio, and growth factor from the recently revised BEA series - focusing on the 1982:1-1998:4 sample for comparison purposes - expressed in chained 1996 prices. Output is approximated by Real GDP, investment by Real Fixed Private Investment, and capital by Real Fixed Private Assets; all variables are normalized with respect to the Civilian Non-Institutional Population (16 years and over). The growth factor, the investment share, and the capital-output ratio are, respectively, $\gamma=1.0050$, $s_{i}=0.14$, and $k / y=8.86$. The implied values for the calibrated parameters are $\alpha=0.71$ and $\delta=1.11 \%$.

Using the procedure outlined in Section 3, p. 13, together with an observed series for the employment rate - obtained as the ratio between Civilian Employment (16 years and over) and the Civilian Non-Institutional Population (16 years and over) - we estimate the stochastic properties of our approximated measure of TFP, plotted in Figure 10. ${ }^{24}$ The resulting figures for the persistence parameter and the standard deviations of productivity shocks are respectively $\rho=0.90$ and $\sigma=0.0046$.

\footnotetext{
${ }^{24}$ The long-run employment rate is equal to 0.62 ; the calibrated value for the scale parameter $\varphi$ is 0.0081 . As far as the quarterly series for physical capital is concerned, we observe a dramatic increase in the implied depreciation rates from 1992:I onwards. As already noted, this variability should reflect a change in the composition of physical capital more than the effect of variable capital utilization.
} 
As in Section 4.2.3, p. 20, we feed our models with the estimated innovations to TFP. The observed and simulated normalized time series for output, consumption, investment, and employment are again expressed as percentage deviation from their own means, and plotted in Figure 11. The correlations between the observed series and various lags and leads of the corresponding simulated ones are summarized in Table 8.

Interestingly enough, both models perform quite well, generating significantly high values for the previously described correlation coefficients. The coefficients are consistently higher than the ones obtained form the Italian data. Even more interestingly, the RW model outperforms the MU as far as consumption and investment are concerned, while the latter still generates a slightly higher correlation coefficient for employment.

Following the same methodology described in Section 4.2.4, p. 21, we test whether the MU model enjoys a comparative advantage in forecasting the US time series. Results are reported in Table 9, while the forecast errors are plotted in Figure 12.

The MDM statistics suggest that the PMSEs generated by the RW model are significantly - at the $1 \%$ level - lower than the corresponding ones generated by the MU when consumption and investment are considered. The MU model seems still able to generate a lower PMSE for employment, but the difference is not significative, even at the $5 \%$ level.

Our results are mixed. However, no clear evidence in favor of the MU model emerges. On the contrary, the RW model seems the one actually enjoying a comparative advantage in explaining the US business cycles.

\section{Conclusions}

We present a non-Walrasian DSGE model with equilibrium unemployment generated by monopolistic trade unions, denominated Monopoly Union (MU) model. As an alternative, we consider a stochastic version of the well-known Rogerson-Wright (WR) model, a Walrasian model built on a completely different set of assumptions on the structure of asset and labor markets.

The question we ask is whether the MU model enjoys a comparative advantage over the RW in explaining the Italian business cycles, since the former is endowed with a labor market structure which, in our opinion, is more compatible with the Italian institutional framework.

The answer we provide is the following. Even if both models are observationally equivalent in small samples with regard to the standard business cycle statistics, by extend- 
ing the comparison metric we conclude that the MU model is able to generate more persistent impulse response functions, and furthermore enjoys a statistically significant comparative advantage in replicating the cyclical components of the main Italian series.

The previous conclusion would be strengthened if the MU model's comparative advantage disappears as the focus moves to a country characterized by a more competitive labor market. Calibrating our toy models on the US economy and replicating the previous experiments, we show that this seems actually the case.

The directions for future research are several. First of all, one can extend the framework to a small open economy set-up. Then, a natural step forward is to consider the implications of the framework for the international business cycles across European countries. Finally, it is interesting to evaluate the effect on the European business cycle of a more centralized wage bargaining process among the European Union members. 


\section{References}

Anderson, S. and M. Devereux (1988), Trade Unions and the Choice of Capital Stock, Scandinavian Journal of Economics, 90, 27-44

Blanchard, O. and C. Kahn (1980), Solution of Linear Difference Models Under Rational Expectations, Econometrica, 38, 1305-1311

Benhabib, J., R. Rogerson, and R. Wright (1991), Homework in Macroeconomics: Household Production and Aggregate Fluctuations, Journal of Political Economy, 99, $1166-1187$

Bertola, G. and A. Ichino (1995), Crossing the River: a Comparative Perspective on Italian Employment Dynamics, Economic Policy, 21, 359-420

Chari, V.V., P. Kehoe, and E. McGrattan (1998), Sticky Price Models of the Business Cycle: Can the Contract Multiplier Solve the Persistence Problem?, Federal Reserve Bank of Minneapolis Research Department Staff Report \#217

Danthine, J. and J. Donaldson (1995), Non-Walrasian Economies, in T. Cooley (ed.), Frontiers of Business Cycles Research, Princeton University Press, Princeton, 217242

Daveri, F. and M. Maffezzoli (2000), A Numerical Approach to Fiscal Policy, Unemployment and Growth in Europe, Econometrics and Applied Economics Working Paper \#2000-4, Institute of Economics, Bocconi University

Diebold, F. X. and R. S. Mariano (1995), Comparing Predictive Accuracy, Journal of Business and Economic Statistics, 13, 253-63

Dunlop, J. (1944), Wage Determination Under Trade Unions, New York, MacMillan

Gali, J. (1995), Non-Walrasian Unemployment Fluctuations, NBER Working Paper \#5337

Gali, J. (1996), Unemployment in Dynamic General Equilibrium Economies, European Economic Review, 40, 839-845

Gomes, J., J. Greenwood, and S. Rebelo (1997), Equilibrium Unemployment, NBER Working Paper \#5922 
Hall, R. (1998), Labor-market Frictions and Employment Fluctuations, NBER Working Paper \#6501, forthcoming in M. Woodford and J. Taylor (eds.), Handbook of Macroeconomics, Vol. IB, Elsevier

Hansen, G. (1985), Indivisible Labor and the Business Cycle, Journal of Monetary Economics, 16, 309-28

Hansen, G. and R. Wright (1992), The Labor Market in Real Business Cycle Theory, Federal Reserve Bank of Minneapolis Quarterly Review, 16, 2-12

Harvey, D., S. Leybourne, and P. Newbold (1997), Testing the Equality of Prediction Mean Squared Errors, International Journal of Forecasting, 13, 281-91

Hayashi, F. (1982), Tobin's Marginal $q$ and Average $q$ : a Neoclassical Interpretation, Econometrica, 50, 213-24

Horn, H. and A. Wolinsky (1988), Worker Substitutability and Patterns of Unionization, Economic Journal, 98, 484-97

King, R. and S. Rebelo (2000), Resuscitating Real Business Cycles, NBER Working Paper \#7534, forthcoming in M. Woodford and J. Taylor (eds.), Handbook of Macroeconomics, Vol. IB, Elsevier

King, R., C. Plosser, and S. Rebelo (1988), Production, Growth and Business Cycles I: the Basic Neoclassical Model, Journal of Monetary Economics, 21, 195-232

Kydland, F. and E. Prescott (1982), Time to Build and Aggregate Fluctuations, Econometrica, 50, 1345-1370

Long, J. and C. Plosser (1983), Real Business Cycles, Journal of Political Economy, 91, 39-69

Manning, A. (1987), An Integration of Trade Union Models in a Sequential Bargaining Framework, Economic Journal, 97, 121-39

OECD (1997), Economic Performance and the Structure of Collective Bargaining, Employment Outlook, 65-91

Oswald, A. (1982), The Microeconomic Theory of the Trade Union, Economic Journal, 92, 269-83

Pissarides, C. (1998), The Impact of Employment Tax Cuts on Unemployment and Wages; The Role of Unemployment Benefits and Tax Structure, European Economic Review, 42, 155-183 
Pencavel, J. (1986), Labor Supply of Men: A Survey, in O. Ashenfelter and R. Layard (eds.), Handbook of Labor Economics, North Holland, Amsterdam, 3-102

Rogerson, R. (1988), Indivisible Labor, Lotteries and Equilibrium, Journal of Monetary Economics, 21, 3-16

Rogerson, R. and R. Wright (1988), Involuntary Unemployment in Economies with Efficient Risk Sharing, Journal of Monetary Economics, 22, 501-15

Westermark, A. (1999), A Model of Union Formation, Working Paper \#1999:8, Department of Economics, Uppsala University 


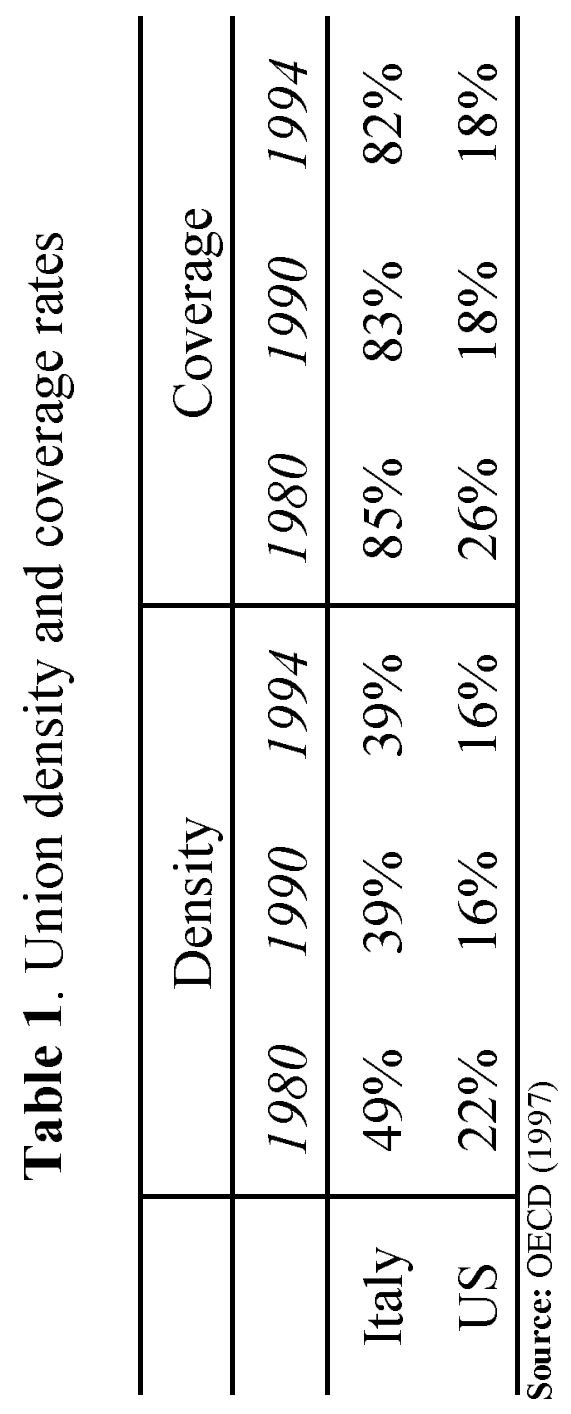




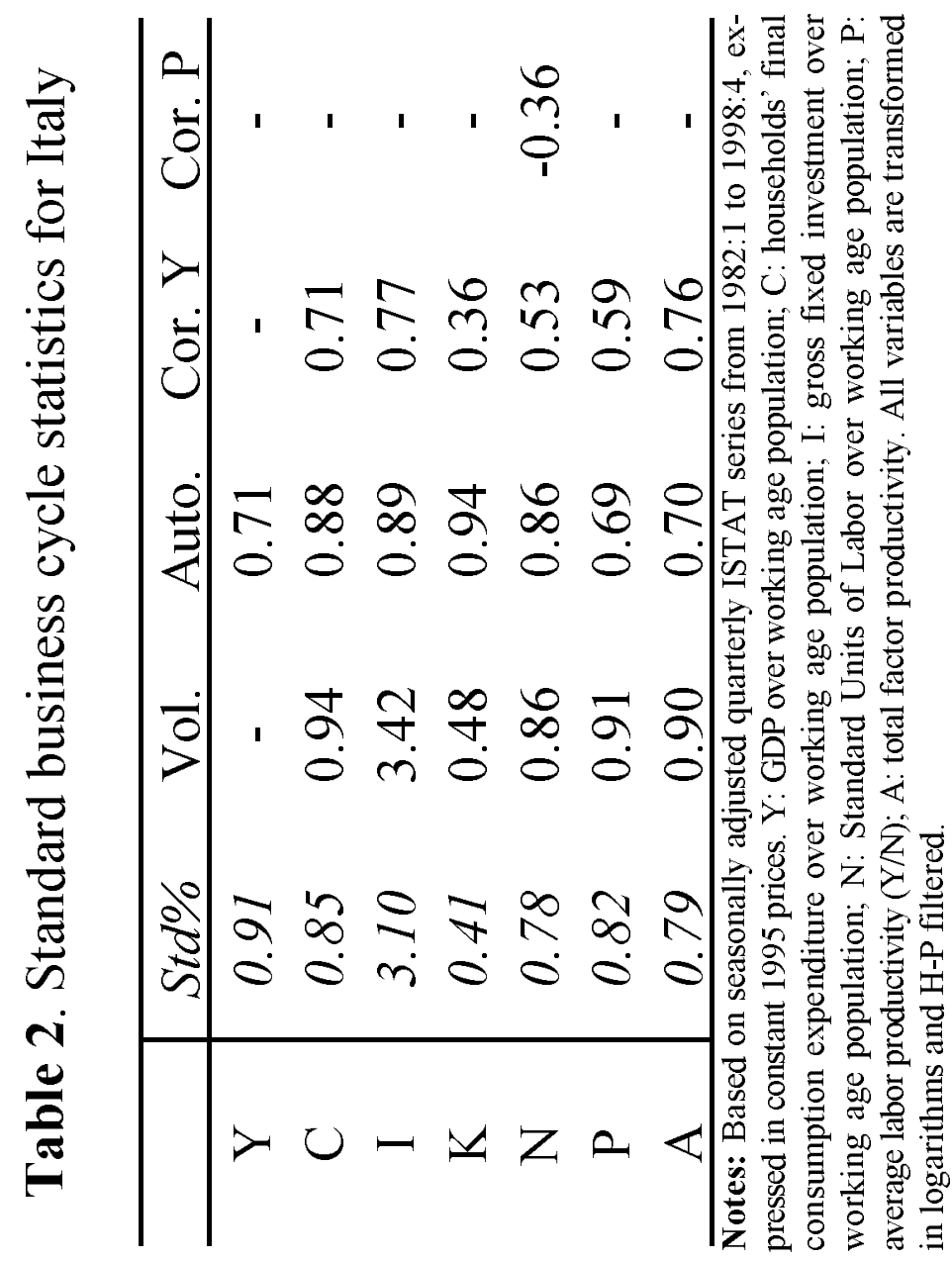




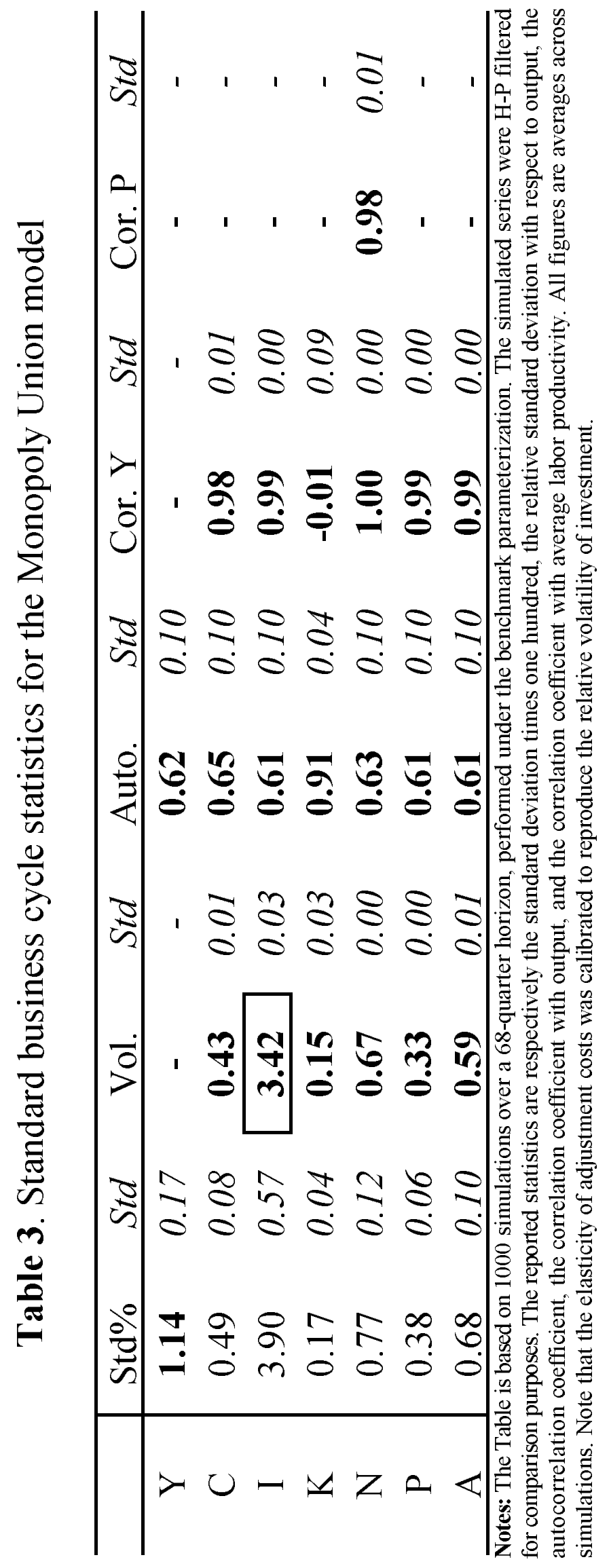




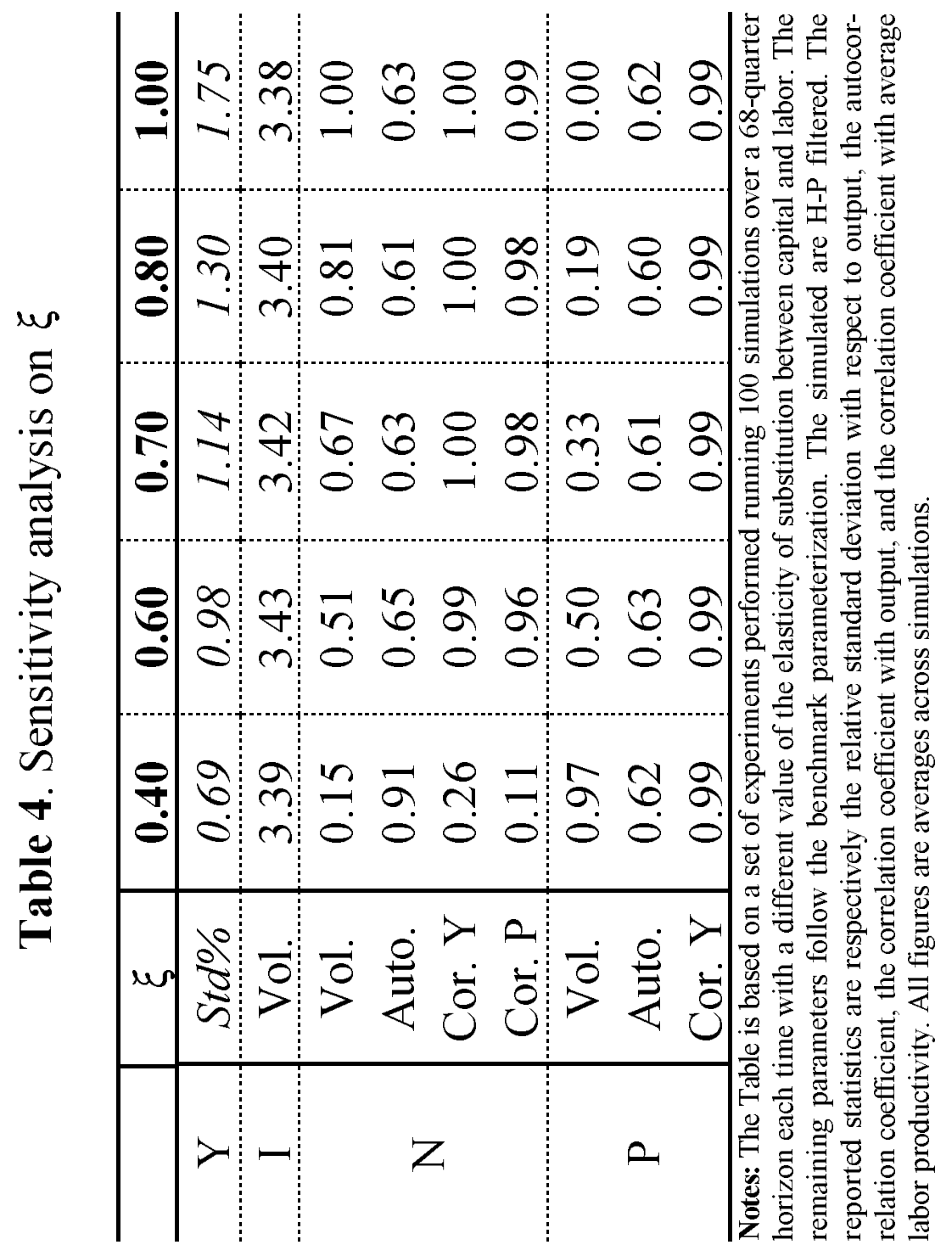




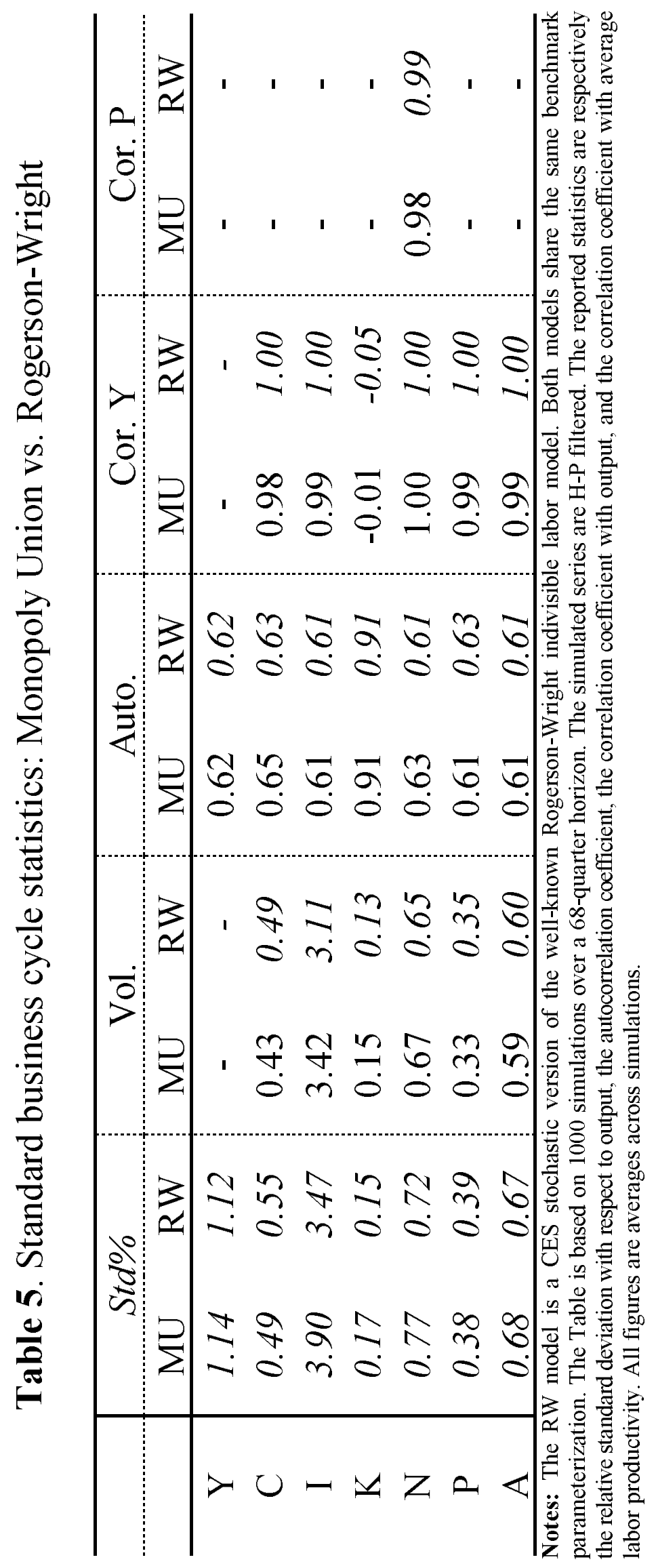




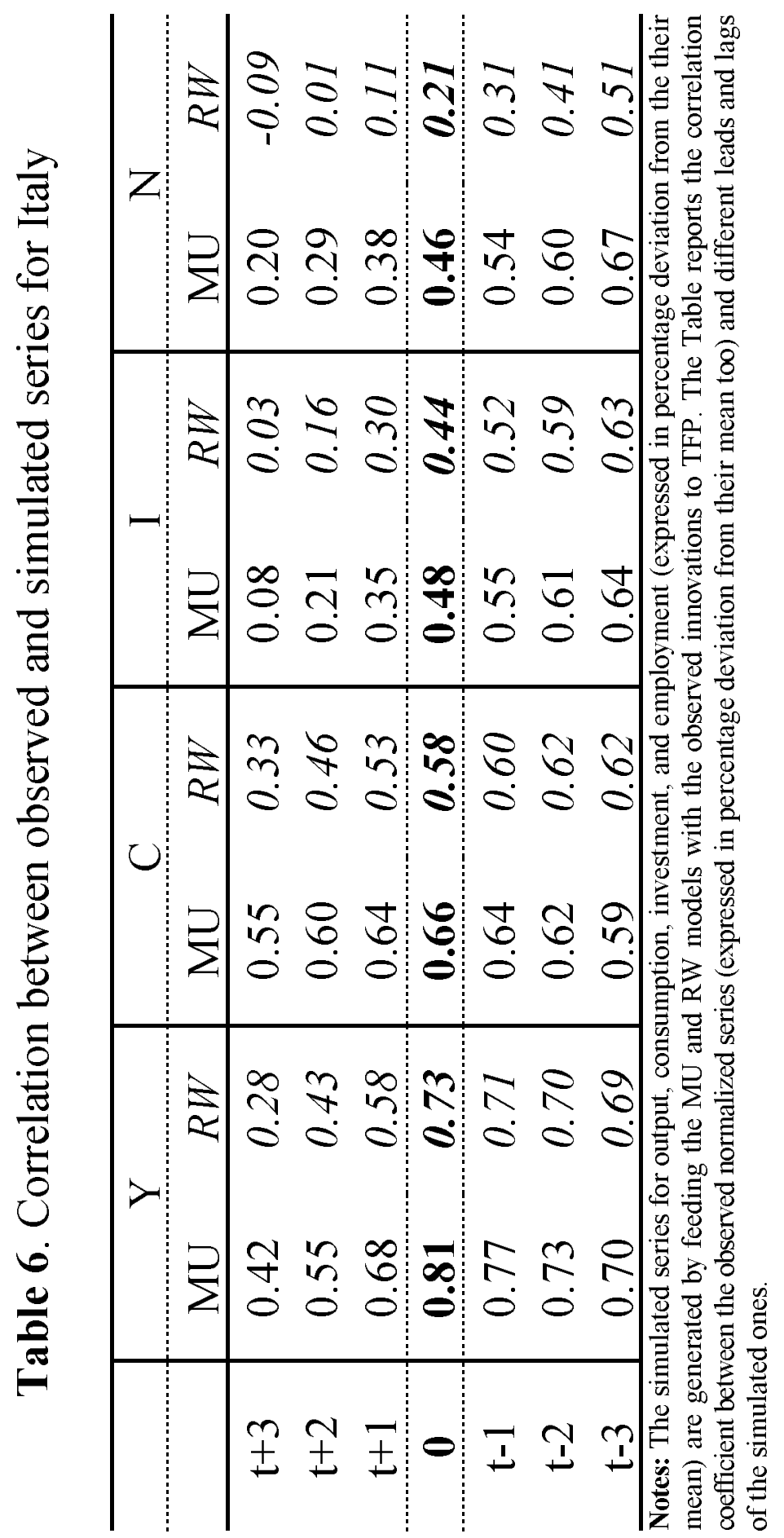




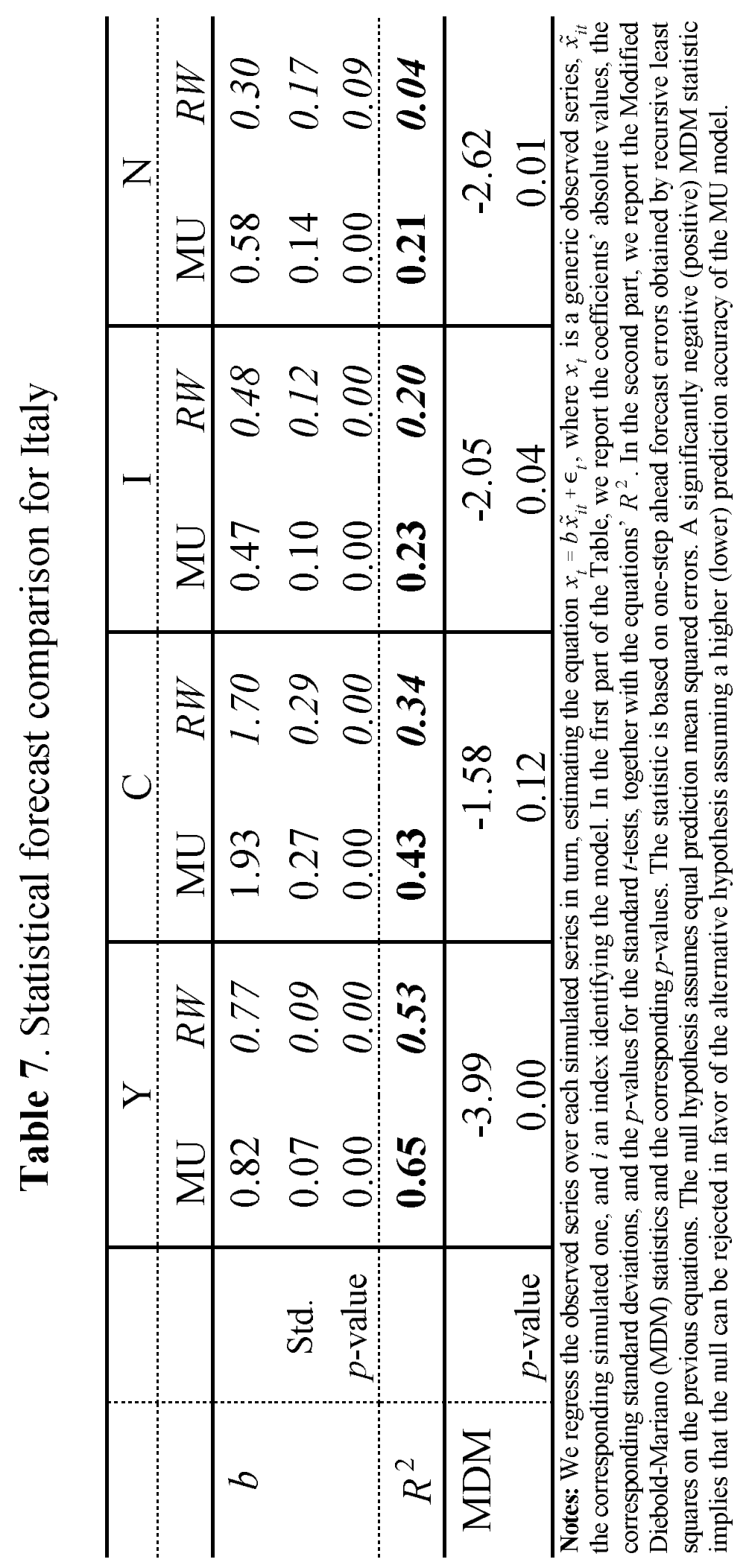




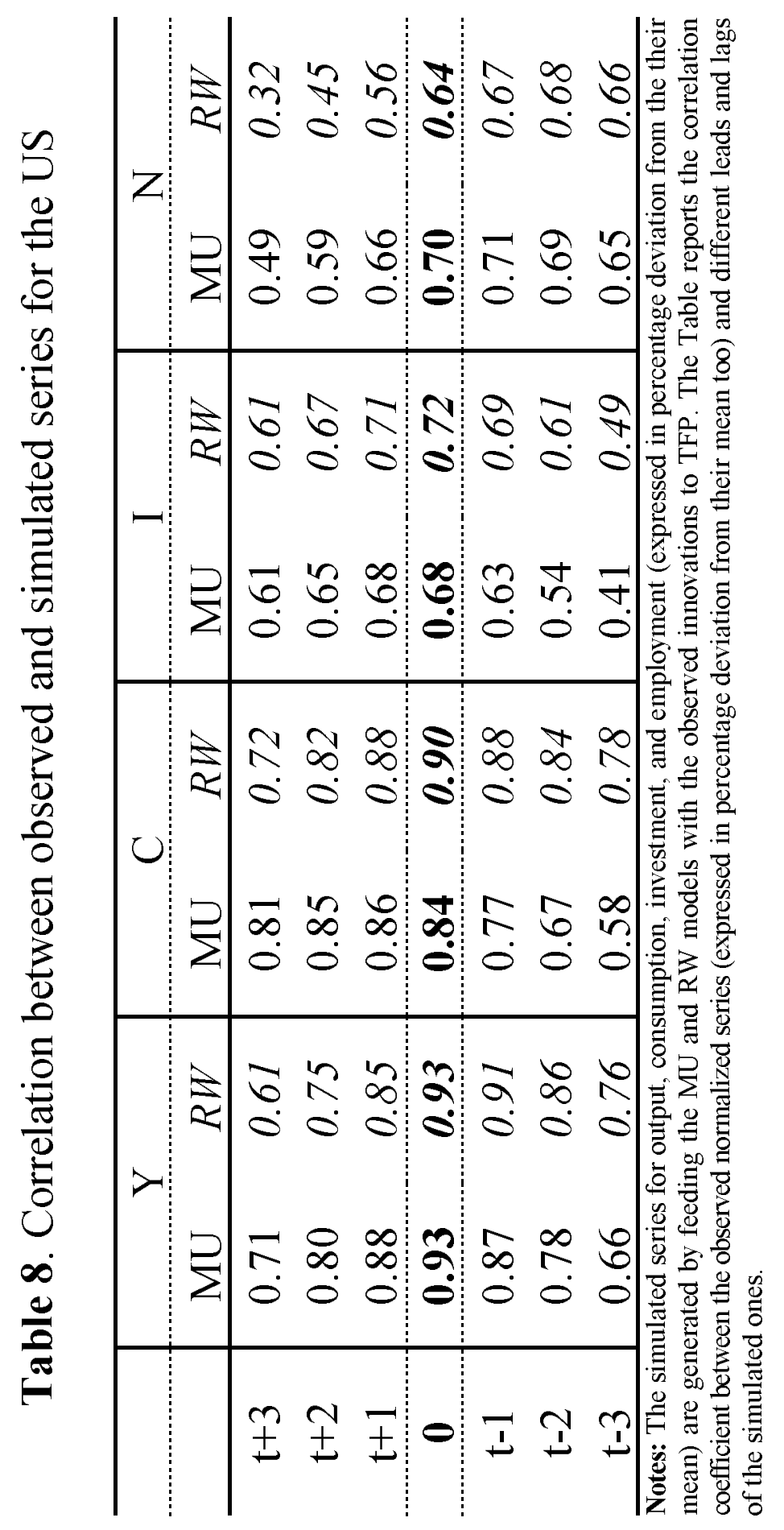




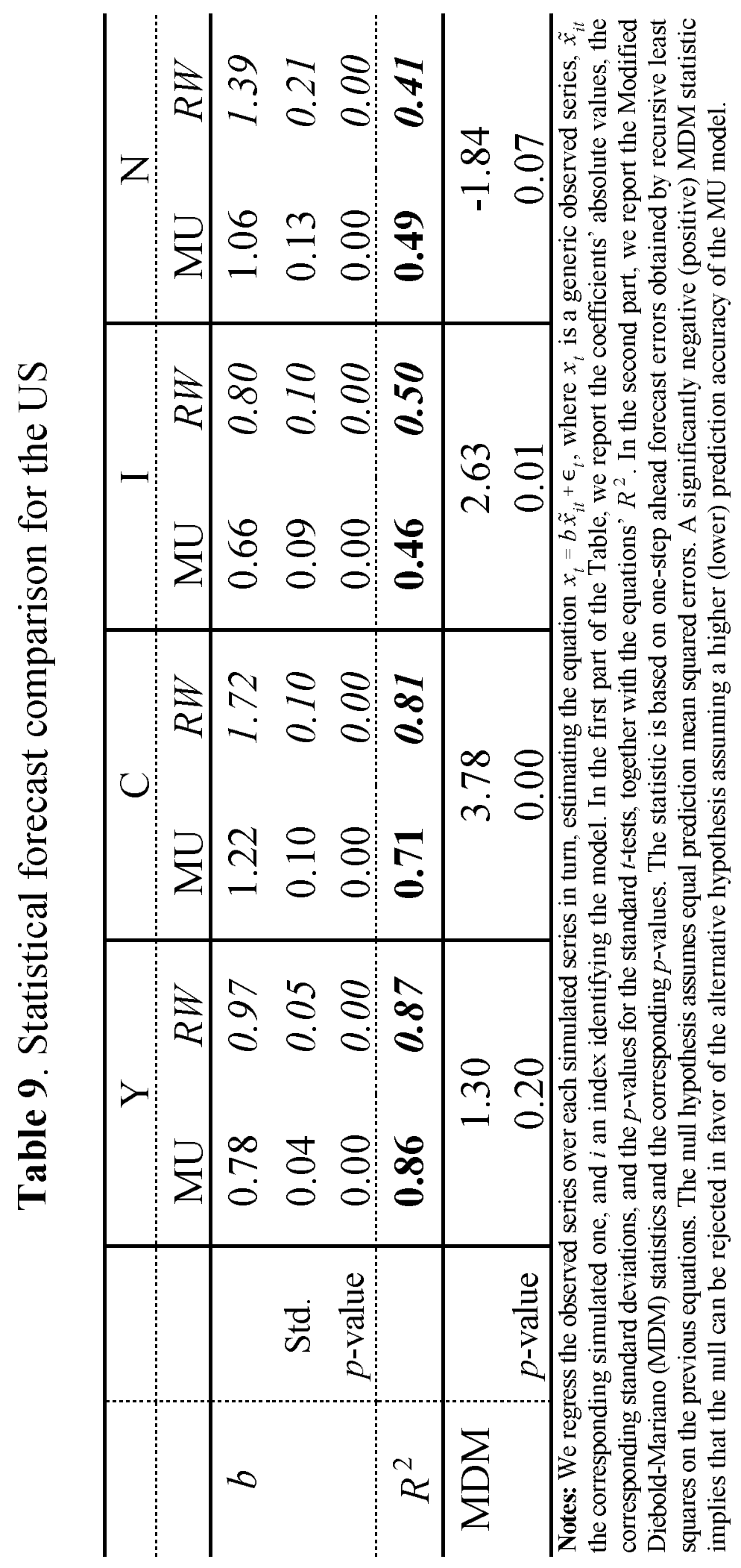




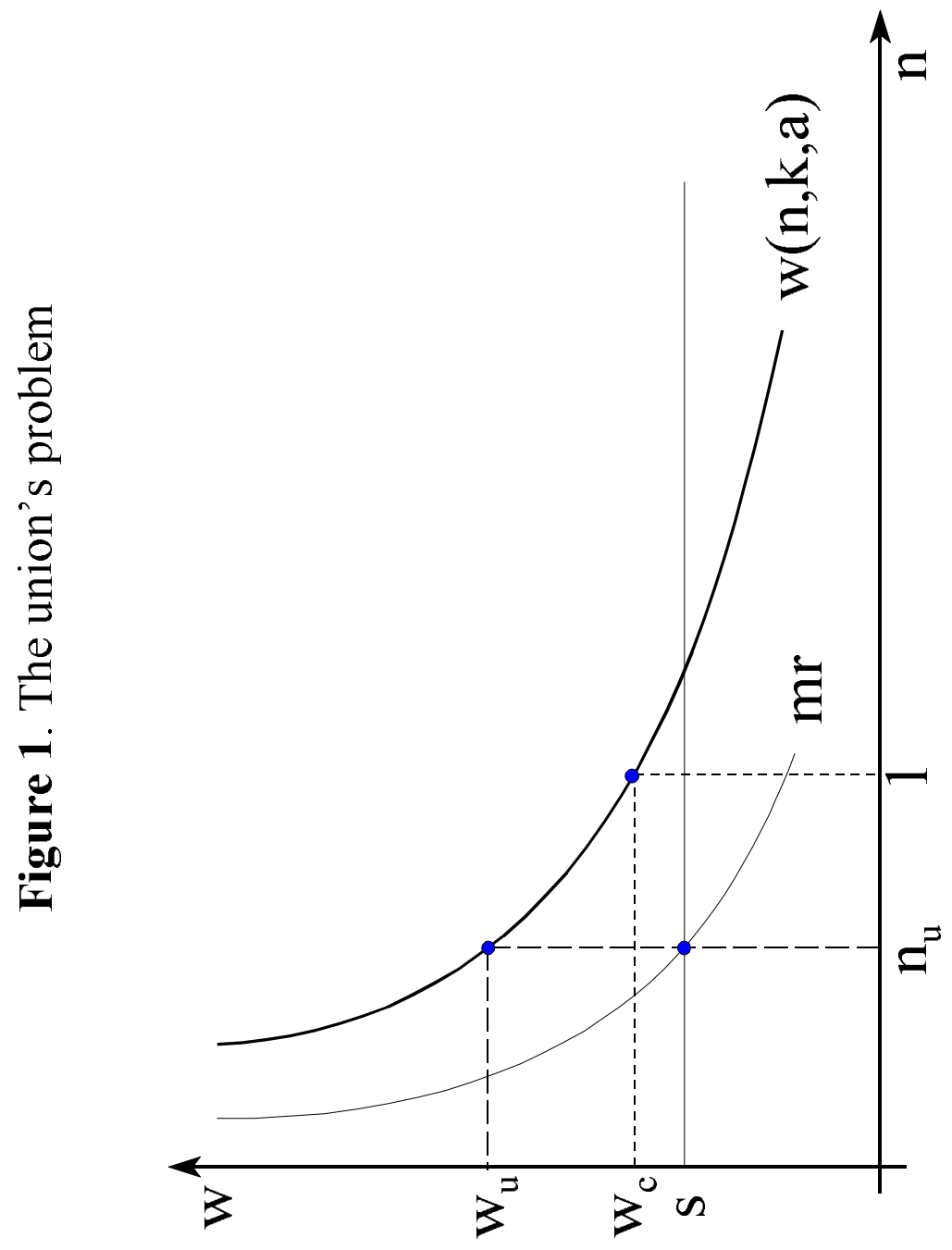




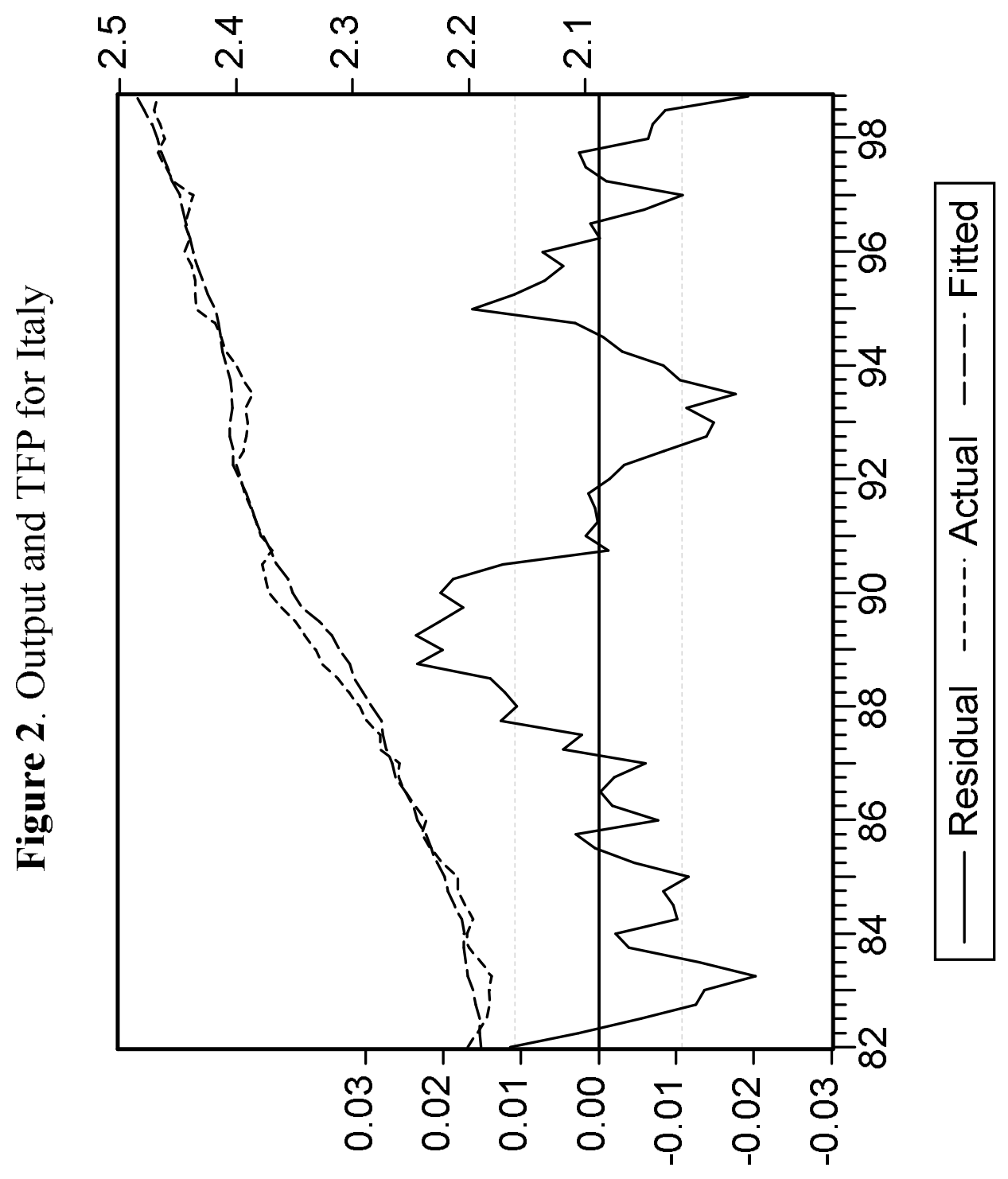




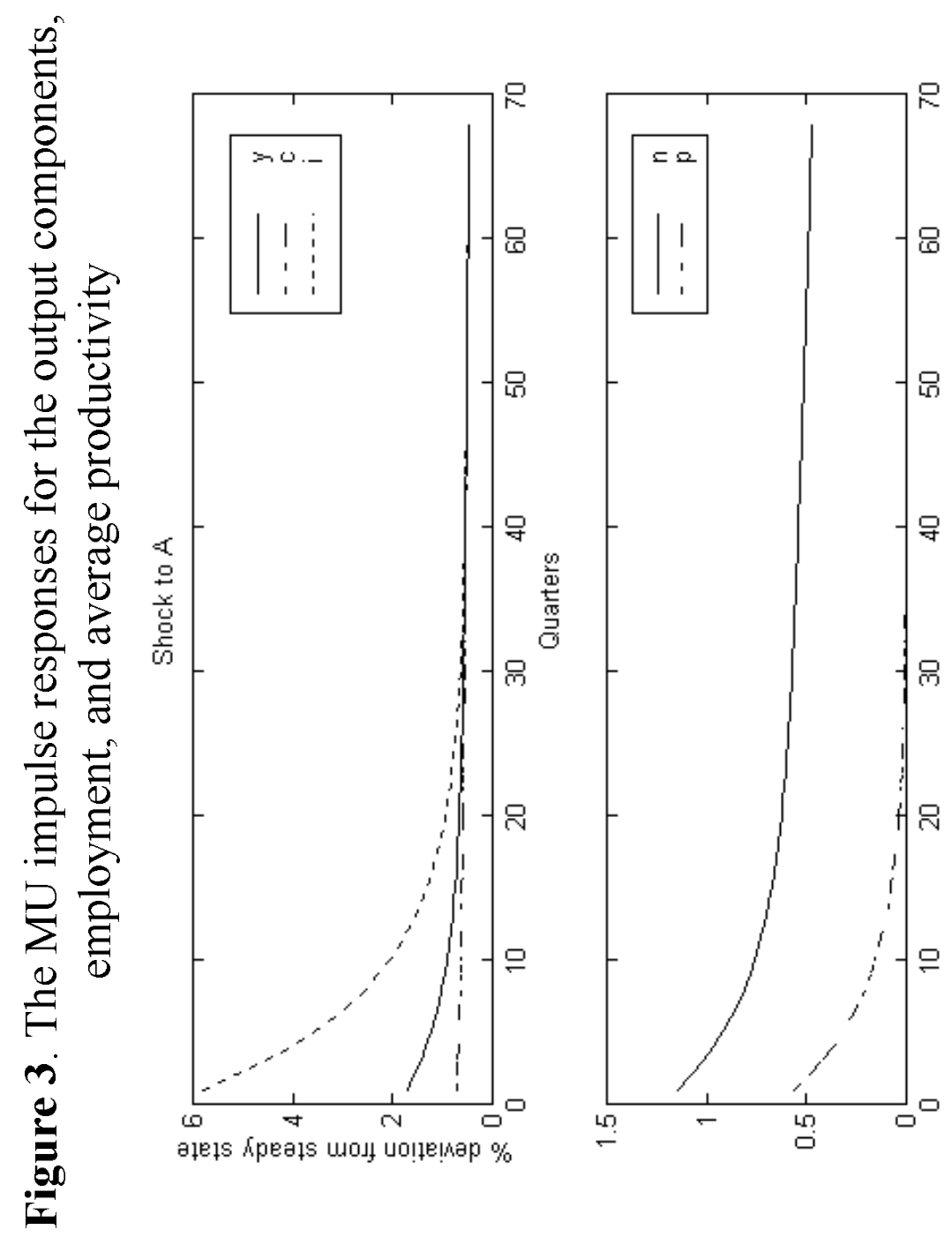




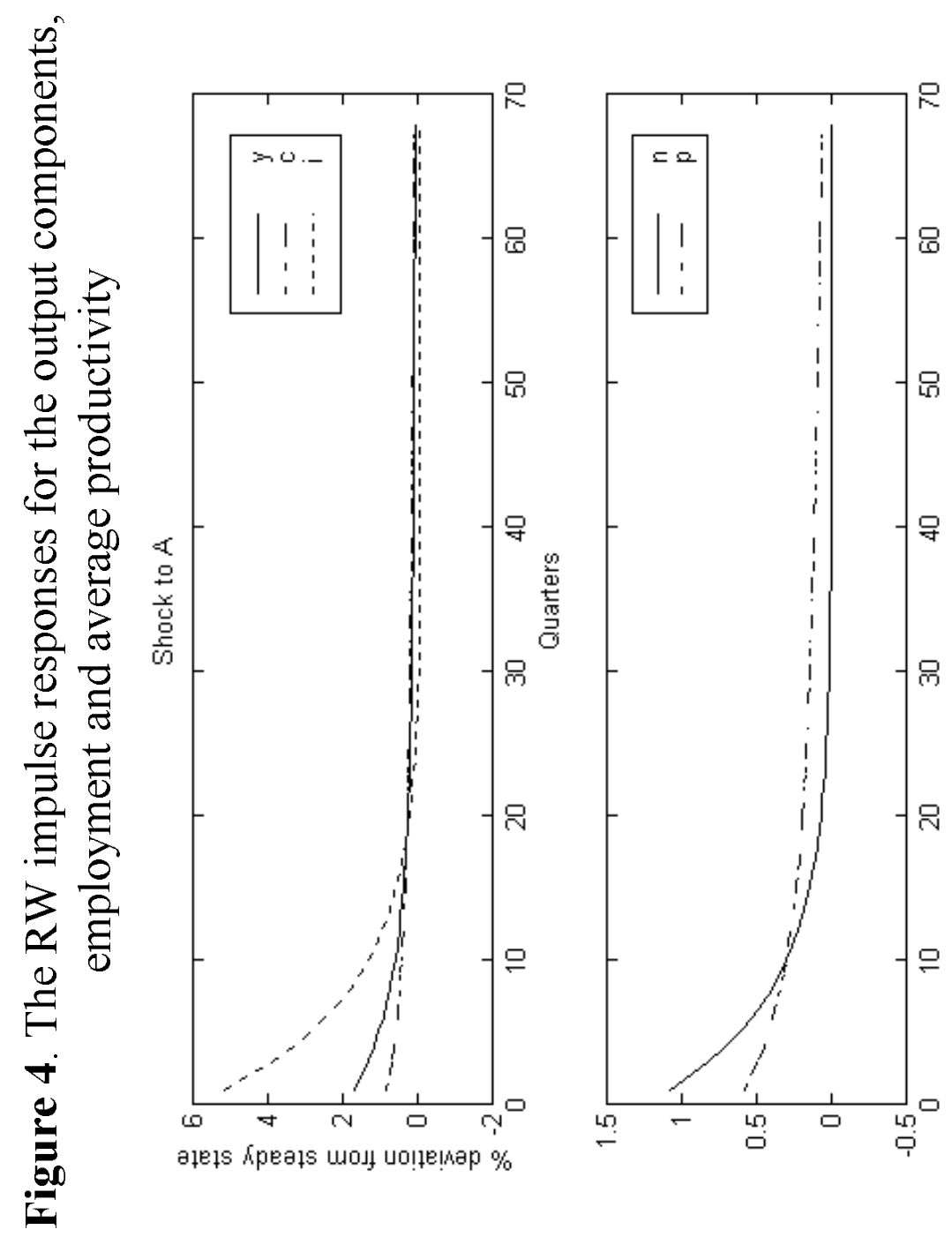




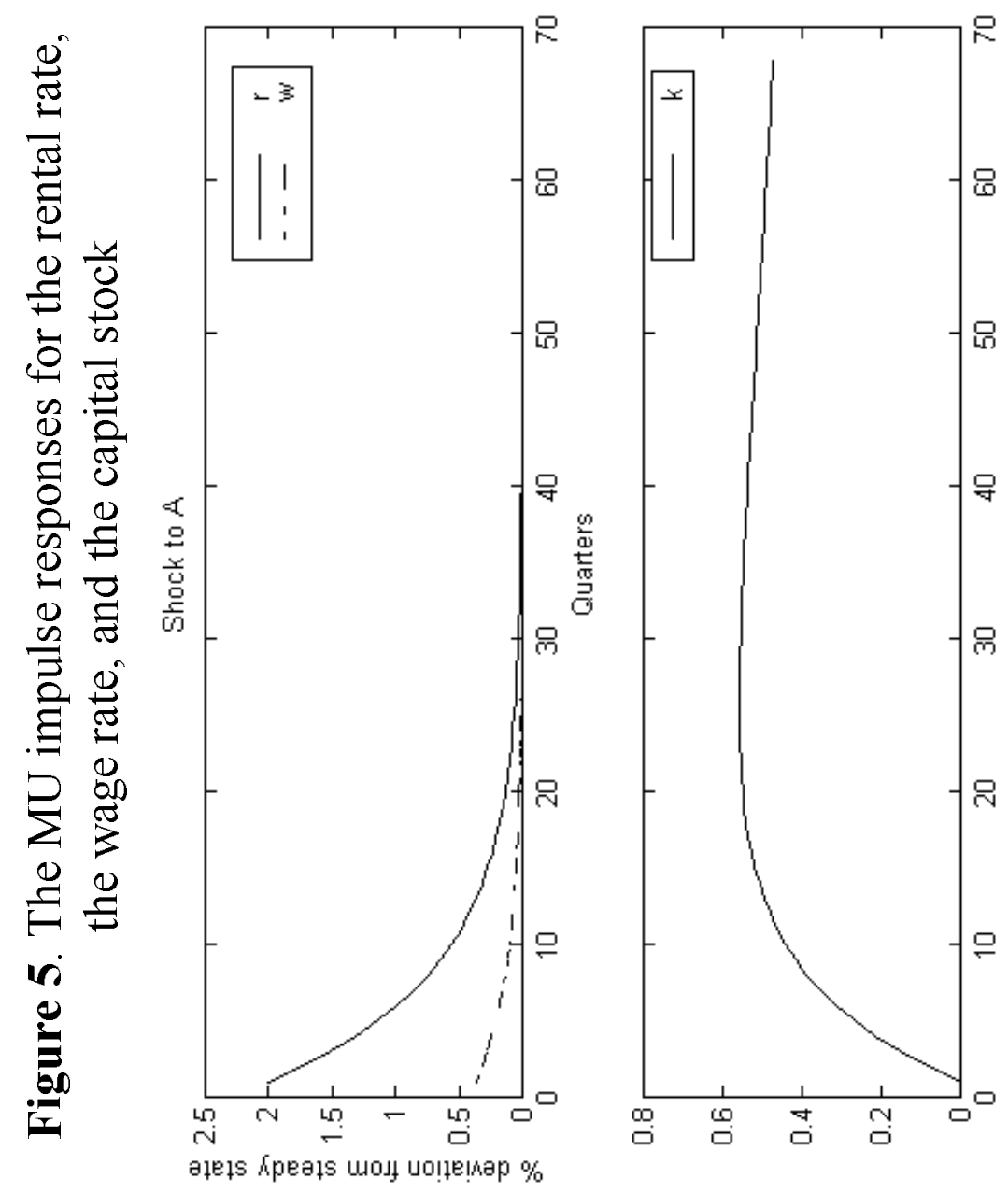




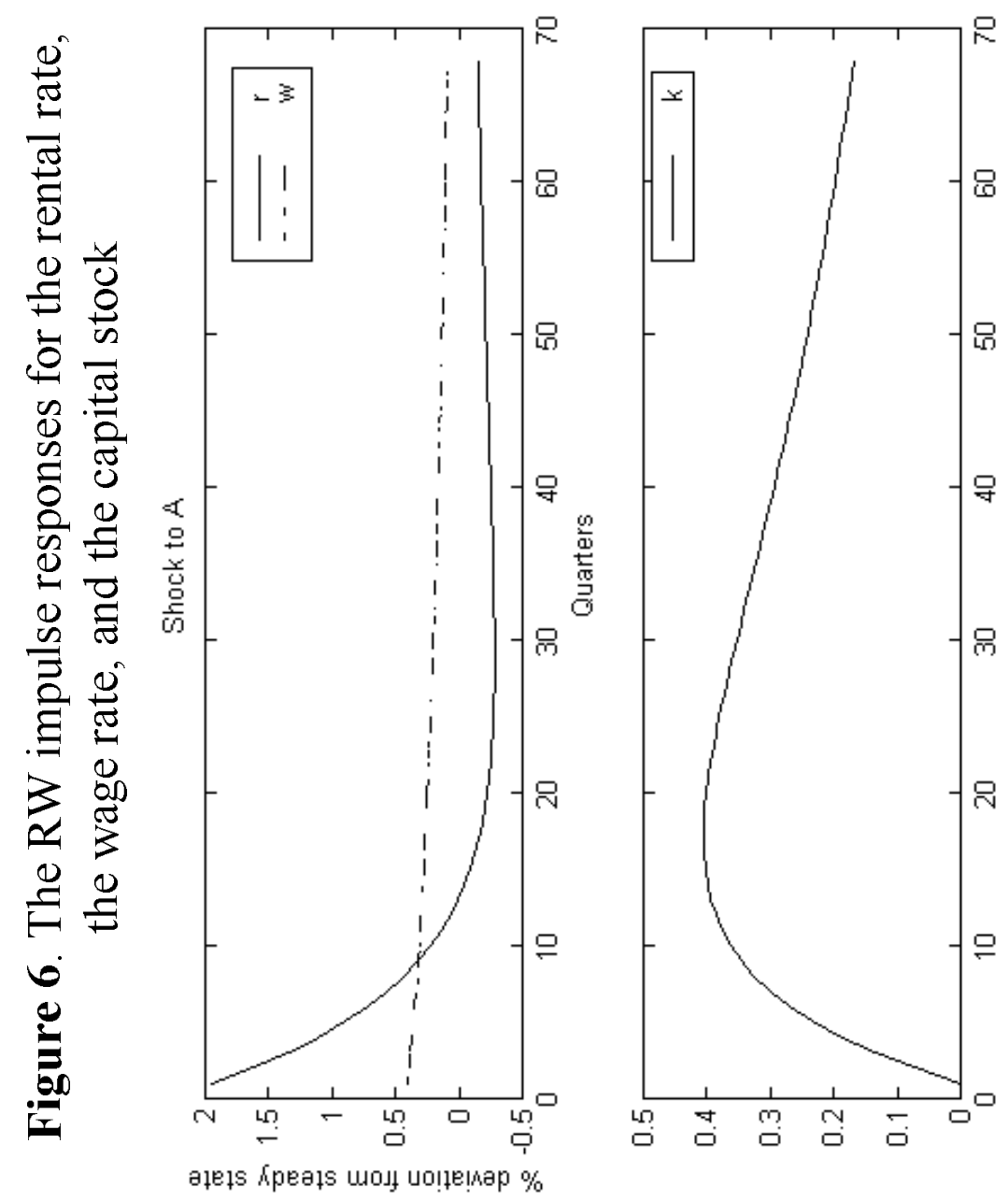




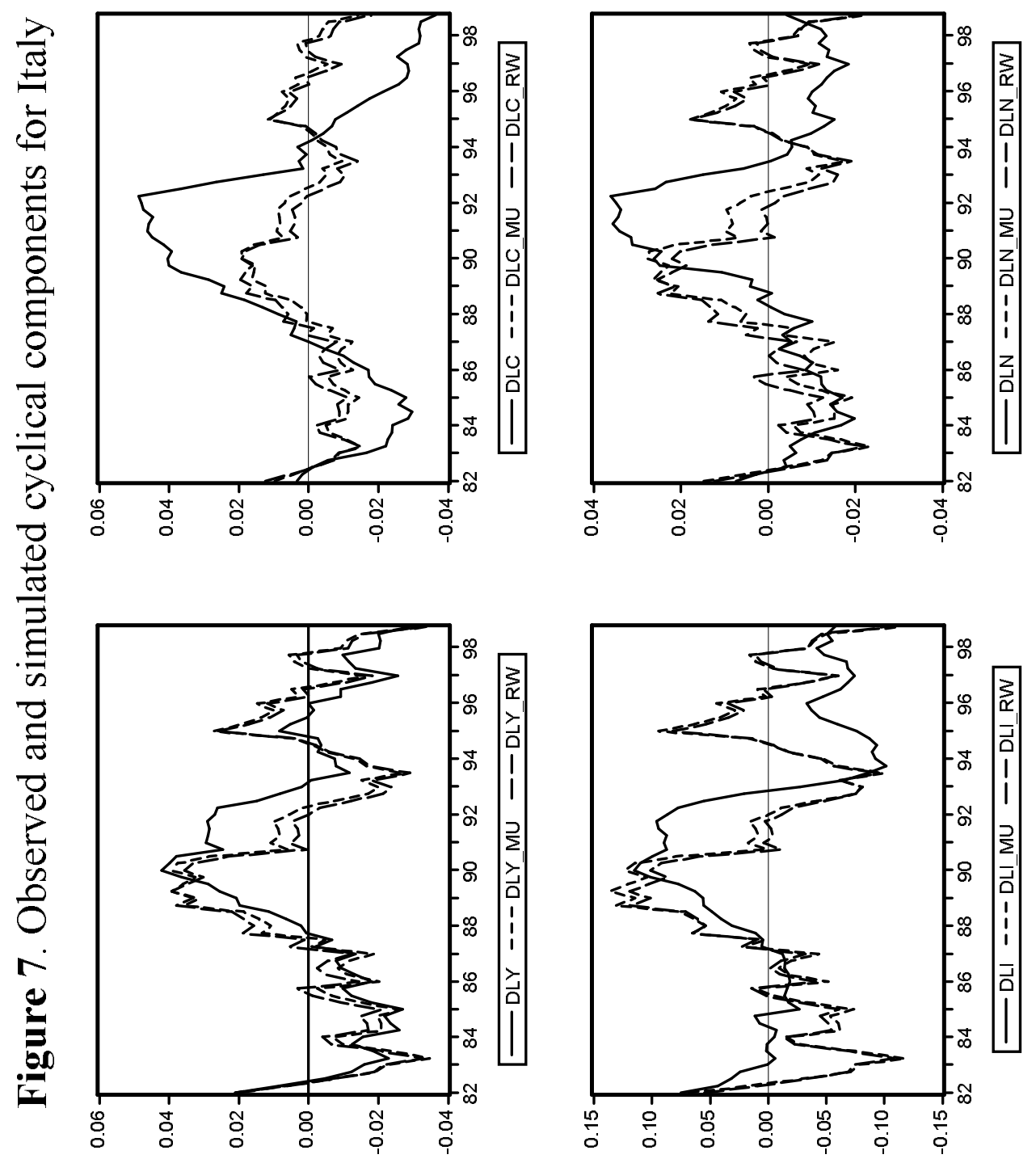




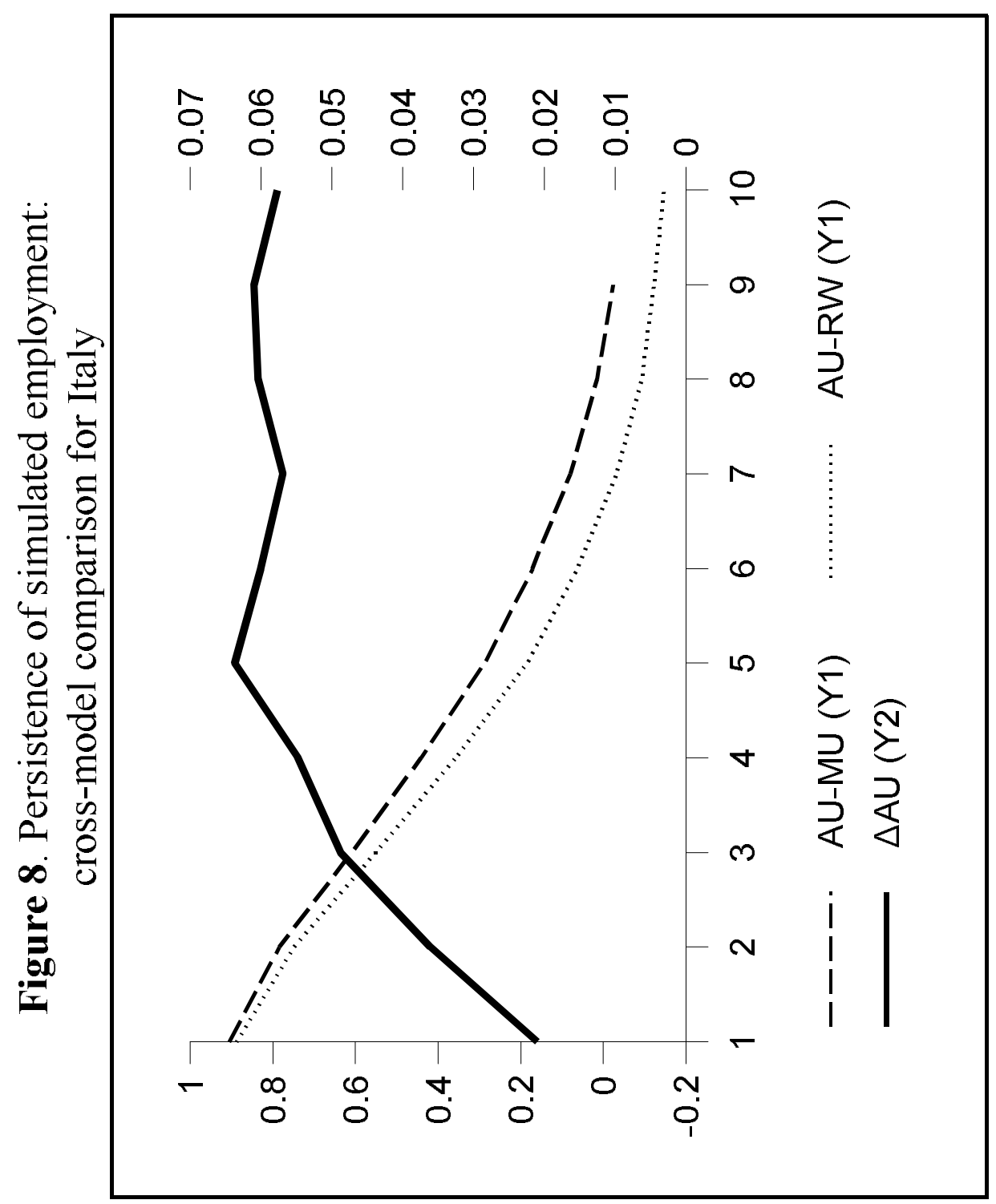




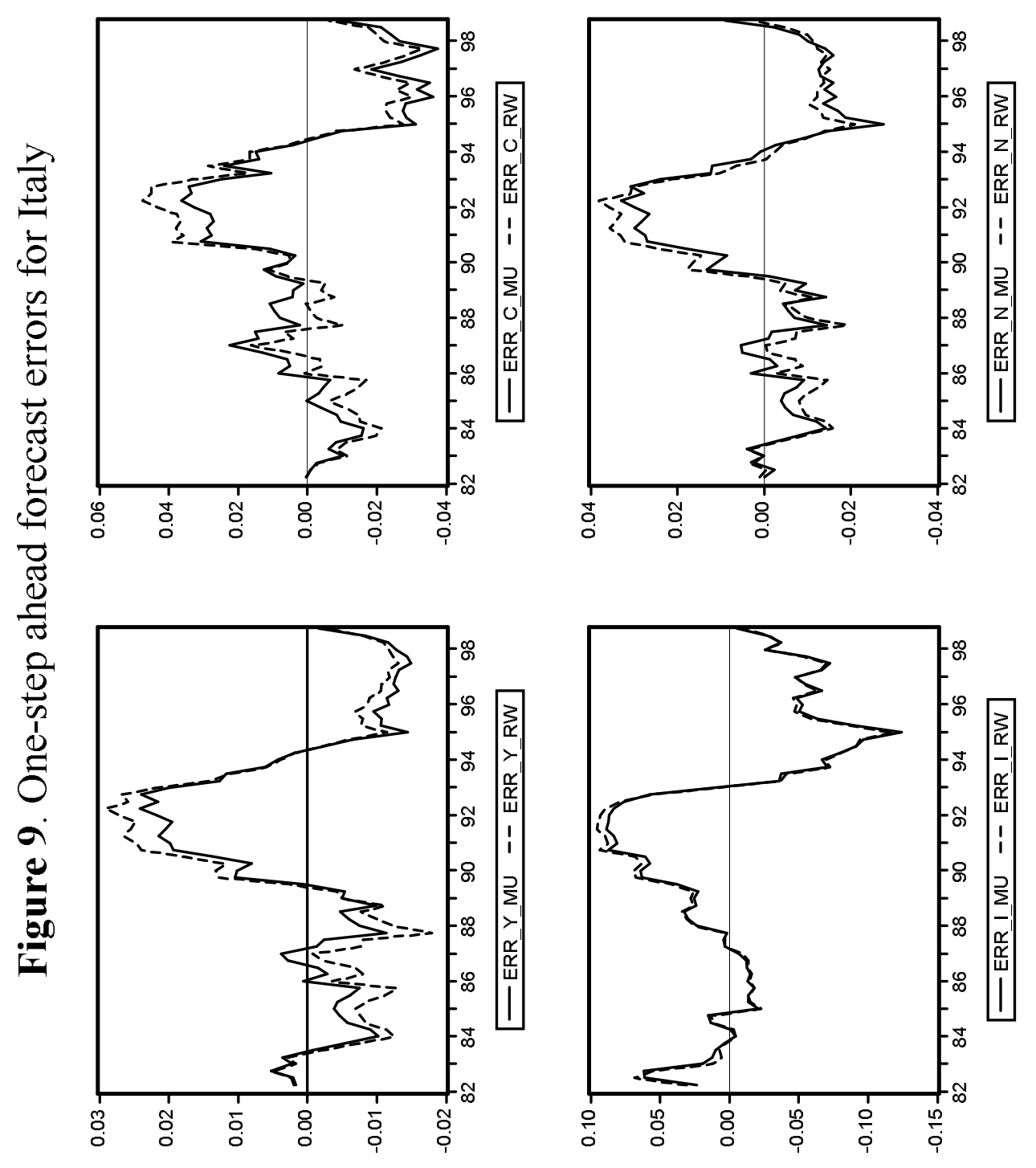




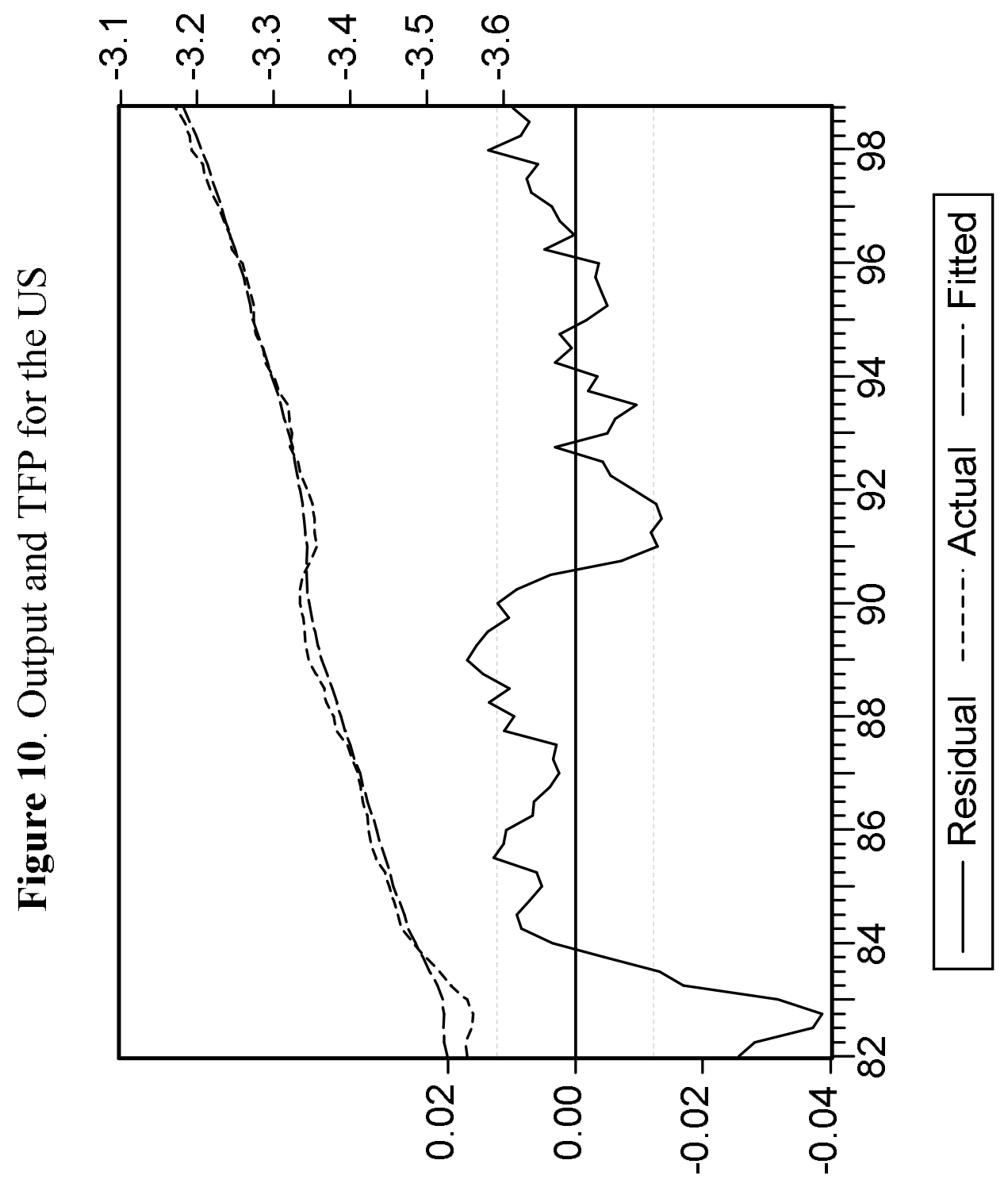




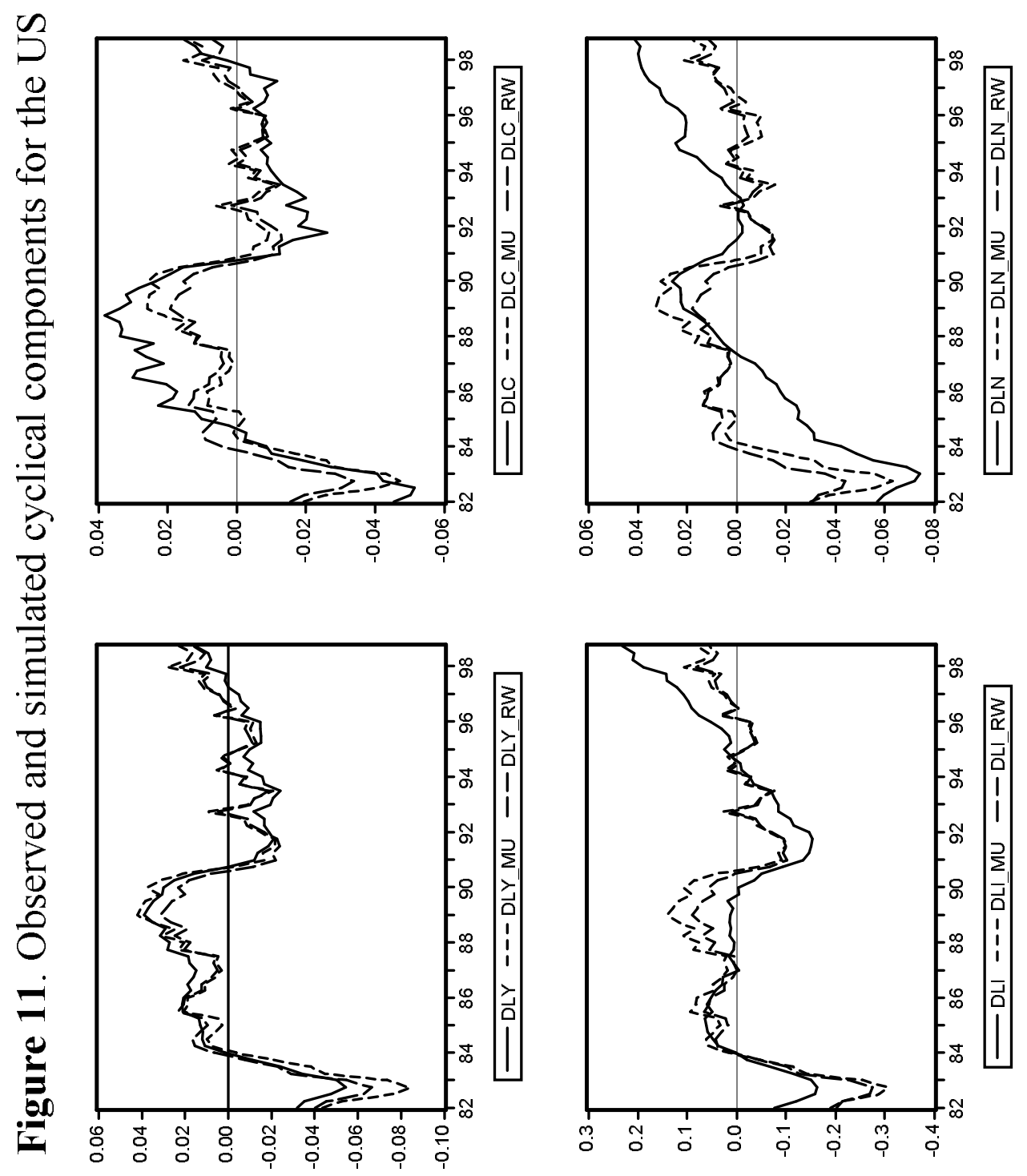




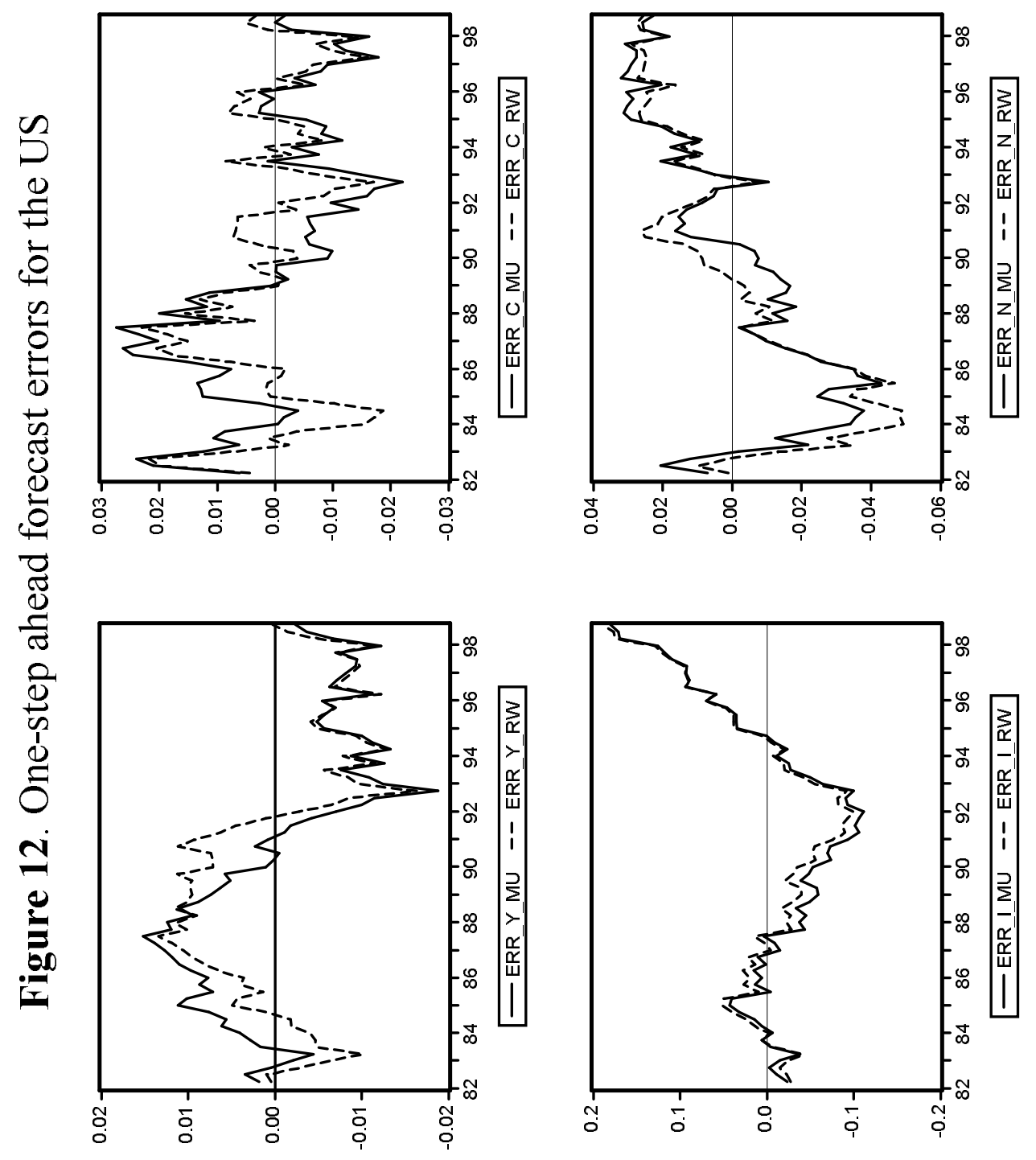

